\title{
Evaluation of Seismic Response Trends from Long-Term Monitoring of Two Instrumented RC Buildings Including Soil-Structure Interaction
}

\author{
Faheem Butt and Piotr Omenzetter \\ Department of Civil and Environmental Engineering, The University of Auckland, Private Bag 92019, Auckland Mail Centre, \\ Auckland, New Zealand \\ Correspondence should be addressed to Piotr Omenzetter, p.omenzetter@auckland.ac.nz
}

Received 14 December 2011; Accepted 7 March 2012

Academic Editor: Rajesh Prasad Dhakal

Copyright ( $) 2012$ F. Butt and P. Omenzetter. This is an open access article distributed under the Creative Commons Attribution License, which permits unrestricted use, distribution, and reproduction in any medium, provided the original work is properly cited.

This paper presents analyses of the seismic responses of two reinforced concrete buildings monitored for a period of more than two years. One of the structures was a three-storey reinforced concrete (RC) frame building with a shear core, while the other was a three-storey RC frame building without a core. Both buildings are part of the same large complex but are seismically separated from the rest of it. Statistical analysis of the relationships between maximum free field accelerations and responses at different points on the buildings was conducted and demonstrated strong correlation between those. System identification studies using recorded accelerations were undertaken and revealed that natural frequencies and damping ratios of the building structures vary during different earthquake excitations. This variation was statistically examined and relationships between identified natural frequencies and damping ratios, and the peak response acceleration at the roof level were developed. A general trend of decreasing modal frequencies and increasing damping ratios was observed with increased level of shaking and response. Moreover, the influence of soil structure interaction (SSI) on the modal characteristics was evaluated. SSI effects decreased the modal frequencies and increased some of the damping ratios.

\section{Introduction}

The characterization of the response of existing civil structures under extreme loading events, such as earthquakes, is a challenging problem that has gained increasing attention in recent years. The challenges associated with the civil structures such as buildings, bridges, and dams include modelling their complicated interaction with the surrounding soil, varying environmental and loading conditions, and complex material and structural behaviours which preclude the study of a complete system in a laboratory setting. To avoid these limitations responses recorded on instrumented structures can be utilized in research $[1,2]$. The in situ measured responses are influenced by all physical properties of the structure and surrounding soil and can be used for better understanding of structural behaviour, health monitoring, and model updating studies $[3,4]$.
In characterizing the dynamic response of buildings, natural frequencies and damping ratios are very important parameters. Permanent instrumentation of buildings makes it possible to study these parameters under different earthquakes excitation. Previous studies have shown that the dynamic characteristics often vary with vibration amplitude [5-7]. It is, therefore, important to examine the behaviour of buildings under different excitation scenarios. The trends in dynamic characteristics, such as modal frequencies and damping ratios, thus developed can provide quantitative data for the variations in the behaviour of buildings. Moreover, such studies can provide useful information for the development and calibration of realistic models for prediction of seismic response of structures in model updating and structural health monitoring studies.

An important aspect in civil engineering structures is soil structure interaction (SSI) which involves transfer of energy 
from ground to structure and back to ground. Mathematically, SSI affects the eigensolutions of the governing equations of motion [8]. Due to the flexibility and energy dissipation properties of soil, the natural periods will be longer and damping ratios larger than the corresponding periods and damping ratios when SSI is ignored. Because building period and damping have important influence on the design and analysis of earthquake-resistant structures, SSI investigations are necessary to better understand the actual response of structures during earthquakes.

Evaluation of SSI effects during strong motion events was extensively studied in Çelebi and Şafak $[9,10]$, Şafak [11], and Çelebi [7]. In those studies, data from instrumented buildings was analysed using Fourier amplitude spectra which is a frequency domain technique. Stewart and Fenves [12] used a parametric system identification technique to evaluate SSI effects in buildings from strong motion records. For identification of fixed, pseudoflexible and flexible base modal parameters, recordings of base rocking, lateral roof motion, lateral foundation motion, and free field motion were required. That study followed the efforts of Luco [13], which used nonparametric procedures for identification of pseudoflexible and flexible base modal parameters in the frequency domain. Another parametric system identification technique was developed by Lin et al. [14] to study SSI with torsional coupling in building response. They employed a system identification technique using information matrix to extract building parameters from a soil-foundation superstructure system. They used foundation rocking as well as translational and torsional motions of the foundation floor as inputs for system identification.

A major portion of the system identification procedures are concerned with computing polynomial models which are known to give rise to ill-conditioned mathematical problems. This is mostly the case for multiple-input/multiple-output systems. Numerical algorithms for subspace state-space system identification (such as N4SID) can perform better, especially for higher-order systems [15]. Another major advantage is their noniterative nature, which guarantees convergence, insensitivity to initial estimates, and absence of local minima of the objective function. It is therefore recommended that such procedures should be followed in the analysis to provide reliable solutions. N4SID is considered to be one of the most powerful classes of known system identification techniques in the time domain [15] and is, therefore, used in the present study for estimating frequencies, damping ratios, and mode shapes.

The main objective of this paper is to evaluate seismic responses of two instrumented RC buildings using monitoring data collected between November 2007 and February 2010. The relationships between peak ground acceleration (PGA) of the free field and at the base level of the buildings and peak response acceleration (PRA) at the roof level were statistically examined for correlations. Natural frequencies and damping ratios, accounting for SSI, were identified. The relationships between the identified frequencies and damping ratios and PRA were developed using statistical analysis. Moreover, the effect of SSI on the seismic response of the buildings was also evaluated. The contribution of this study is that all the aforementioned relationships are obtained via rigorous statistical analyses using a relatively large number of seismic events, which is still rather rare in the existing literature. While a broader set of metrics and other descriptive terms characterising ground shaking and/or structural response could be considered, for example, peak ground/response velocity and displacement, duration of strong motion, and direction of earthquake as suggested in the context of seismic damage [16-19], such investigations are left out for useful future extensions of the current research.

The outcome of this study is expected to further the understanding of dynamic behaviour of buildings during earthquakes and provide new quantitative data for studying seismic responses of as built structures, structural health monitoring, and model updating studies. The limitation is, however, that only low-to-medium intensity seismic records were available. To extend the present study, more data, including those from high intensity earthquakes are required but are currently not available. The analysed excitation level is, nevertheless, of interest and importance for serviceability limit state studies where structures remain in their elastic, linear, or only mildly nonlinear, range. For example Uma et al. [20] studied the effect of seismic actions on acceleration sensitive, nonstructural components and concluded that the acceleration demands for non-structural components can increase even in the lesser intensity shaking, which can damage them and consequently disrupt operational continuity of buildings. Therefore, a wide range of ground shaking intensities, from low to high, and the corresponding dynamic behaviour of structures should be considered in design to avoid such damage and operational disruption. Also to account for the time-dependent variation of structural response due to aging, environmental agents and consequently degradation of RC structures, the responses to both ultimate and serviceability limit state shaking should be evaluated [21]. Furthermore, low-to-medium shaking levels are important as the baseline data to judge the condition of the structure in structural health monitoring applications [4].

The outline of the paper is as follows. Firstly, the description of the buildings and sensor array is provided. Secondly, the methodology of the study is explained, including a brief introduction to the N4SID technique and its application to the present case, and then a method for evaluation of SSI is discussed. Next, how PGAs at the free field, PGAs at the building base and PRAs are correlated and how natural frequencies and damping ratios change with seismic response amplitude is quantitatively evaluated. Next, SSI effects on modal parameters are discussed. Finally, a set of conclusions summarizes this study.

\section{Description of the Buildings and Instrumentation}

The buildings under study are two blocks of the GNS Science building complex at Avalon, Lower Hutt situated approximately $20 \mathrm{~km}$ northeast of Wellington, New Zealand. 


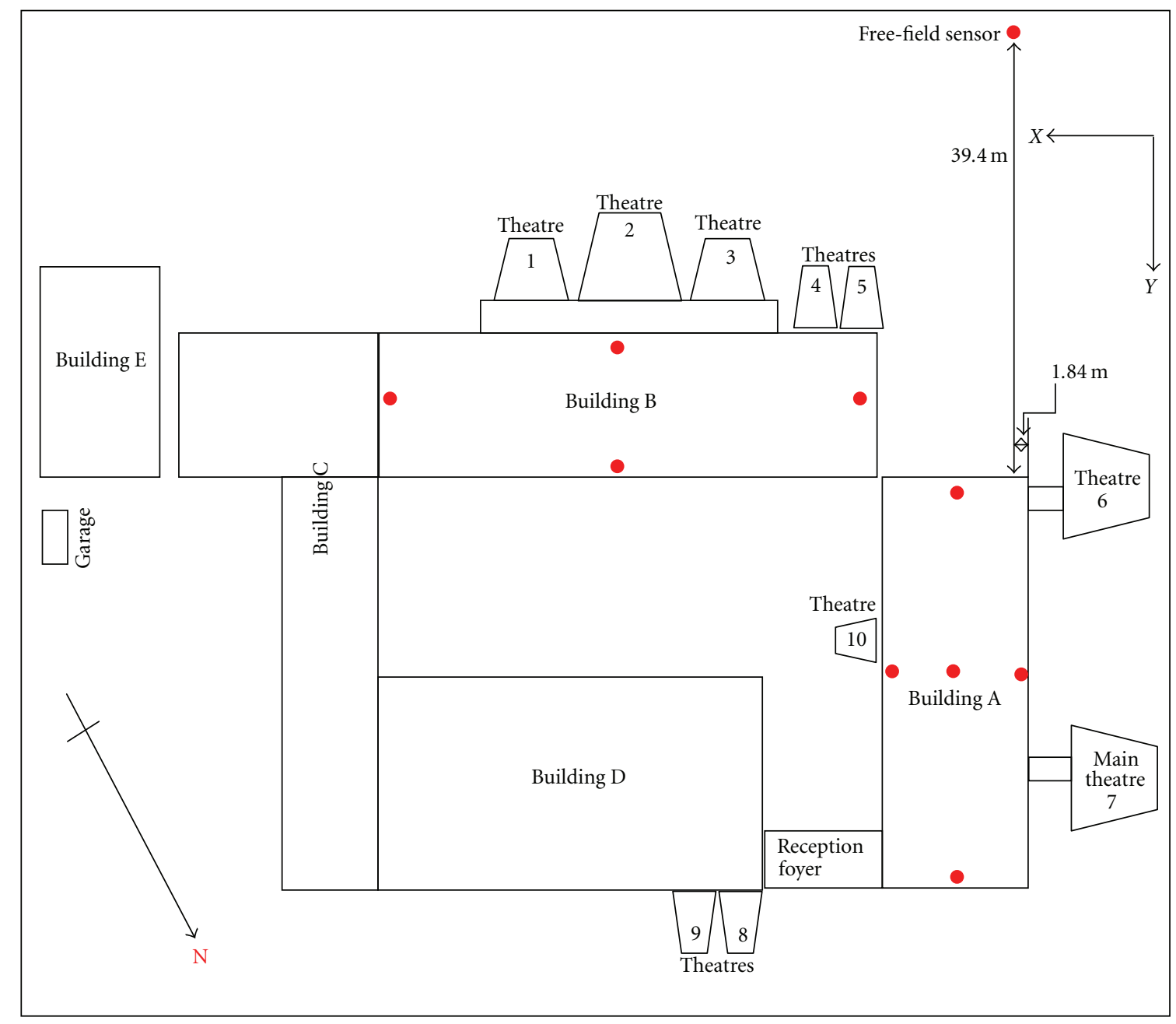

FIGURE 1: Layout of GNS Science building complex at Avalon (red dots show the approximate locations of sensors).

The entire building complex comprises five major blocks (Figure 1) which are structurally separated by expansion joints. Buildings A and B are instrumented with nine triaxial accelerometers in total. There is also a free field triaxial accelerometer mounted at the ground surface and located at $39.4 \mathrm{~m}$ from the south end of building $\mathrm{A}$ as shown in Figure 1. Figure 1 also shows the common global axes $X$ and $Y$ used for identifying directions in the subsequent discussions. All the data is stored to a central recording unit and is available online (http://www.geonet.org.nz/). The detail of the structural systems and sensor arrays of the buildings are discussed in the following sections.

2.1. Building A. Building A is a three-storey RC structure with a basement, $44 \mathrm{~m}$ long, $12.19 \mathrm{~m}$ wide and $13.4 \mathrm{~m}$ high (measured from the base level). The structural system consists of 12 beam-column frames and a $2.54 \mathrm{~m} \times 1.95 \mathrm{~m}$ RC shear core with the wall thickness of $229 \mathrm{~mm}$, which houses an elevator. The plan of the building is rectangular but the beams along the longitudinal direction inside the perimeter beams and the shear core make it unsymmetrical in terms of stiffness distribution (Figure 2(a)). All the beams and columns are of rectangular cross-section. The exterior beams are $762 \times 356 \mathrm{~mm}$ except at the roof level where these are $1067 \times 356 \mathrm{~mm}$. All the interior beams and all columns are $610 \times 610 \mathrm{~mm}$. Floors are $127 \mathrm{~mm}$ thick reinforced concrete slabs except a small portion of the ground floor near the stairs where it is $203 \mathrm{~mm}$ thick. The roof comprises corrugated steel sheets over timber planks supported by steel trusses. The building is resting on separate pad type footings of base dimensions $2.29 \times 2.29 \mathrm{~m}$ at the perimeter and $2.74 \times 2.74 \mathrm{~m}$ inside the perimeter and $610 \times$ $356 \mathrm{~mm}$ tie beams are provided to join all the footings together. This building is instrumented with five tri-axial accelerometers. Two accelerometers are fixed at the base level, one underneath the first floor slab and two at the roof level as shown in Figure 2(b).

2.2. Building $B$. Building $B$ is also a three-storey $\mathrm{RC}$ building with a basement, $56 \mathrm{~m}$ long, $12.19 \mathrm{~m}$ wide, and $13.4 \mathrm{~m}$ high 


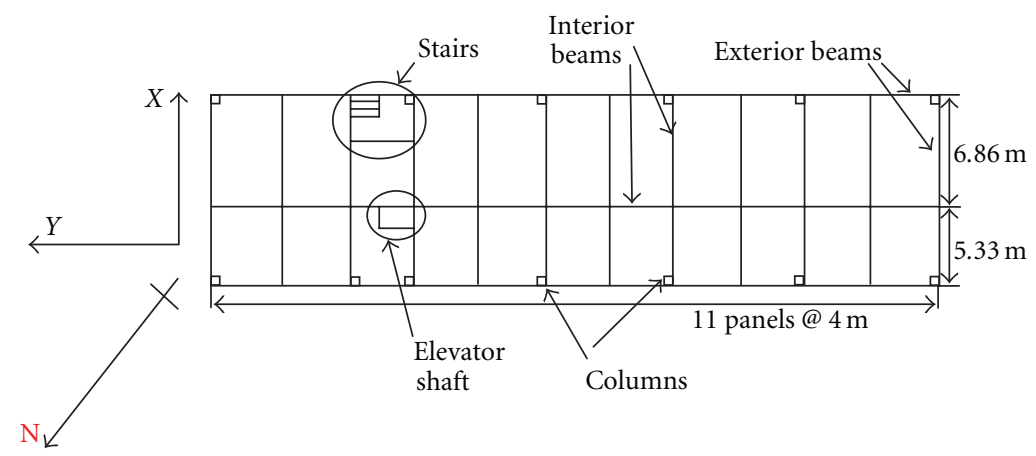

(a)
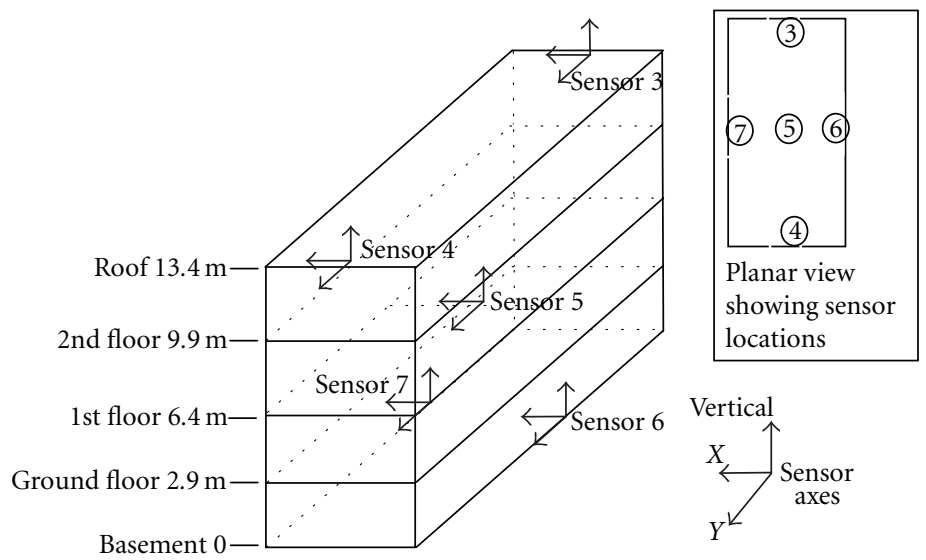

(b)

FIGURE 2: Building A: (a) typical floor plan showing location of stairs and elevator shaft and (b) sensor array.

(measured from the base level). The floor plan is rectangular and the main structural system consists of 15 beam-column frames. Floor heights, frame pattern, the sizes of beams, columns, slabs, tie beams, roof, and foundations are the same as that of building A but there are more frames in longitudinal direction (Figure 3(a)). Unlike in building A, there is no shear core in building $\mathrm{B}$. The building is instrumented with four tri-axial accelerometers: two are fixed at the roof level and two at the base level. Figure 3(b) shows the sensor locations and their sensitive axis directions.

\section{Methodology}

3.1. N4SID System Identification Technique. This section provides a brief explanation of the N4SID system identification technique. Full details of the technique can be found in Van Overschee and De Moor [22]. After sampling of a continuous time state space model, the discrete time state space model can be written as

$$
\begin{gathered}
x_{k+1}=A x_{k}+B u_{k}+w_{k}, \\
y_{k}=C x_{k}+D u_{k}+v_{k},
\end{gathered}
$$

where $A, B, C$, and $D$ are the discrete time state, input, output, and control matrices, respectively, whereas $x_{k}$ and $y_{k}$ are the time state and output vectors and $u_{k}$ is the excitation vector, respectively. Vectors $w_{k}$ and $v_{k}$ are the process and measurement noise, respectively, that are always present in real-life applications. In case of input/output system identification, data from both output $y_{k}$ and input $u_{k}$ are assembled in a block Hankel matrix, which is defined as a gathering of a family of matrices that are created by shifting the data matrices in time. After this, the identification involves two steps. The first step takes projections of certain subspaces calculated from input and output observations (in the block Hankel matrix) to estimate the state sequence of the system. This is usually achieved using singular value decomposition (SVD) and QR decomposition. In the second step, a least square problem is solved to estimate the system matrices $A, B, C$, and $D$. Then the modal parameters, that is, natural frequencies, damping ratios, and mode shapes, are found by eigenvalue decomposition of the system matrix $A$.

3.2. Application of N4SID Technique to the Instrumented Buildings. The N4SID technique derives state-space models for linear systems by applying the well-conditioned operations, like SVD, to the block Hankel data matrices. The analyst, however, has to determine a proper system order. The approach based on observing trends of the estimated 


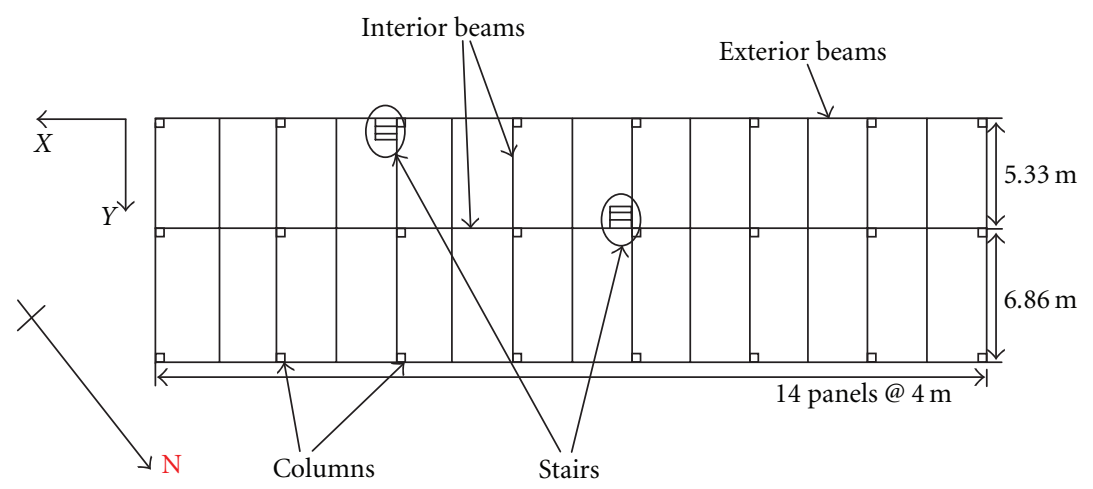

(a)

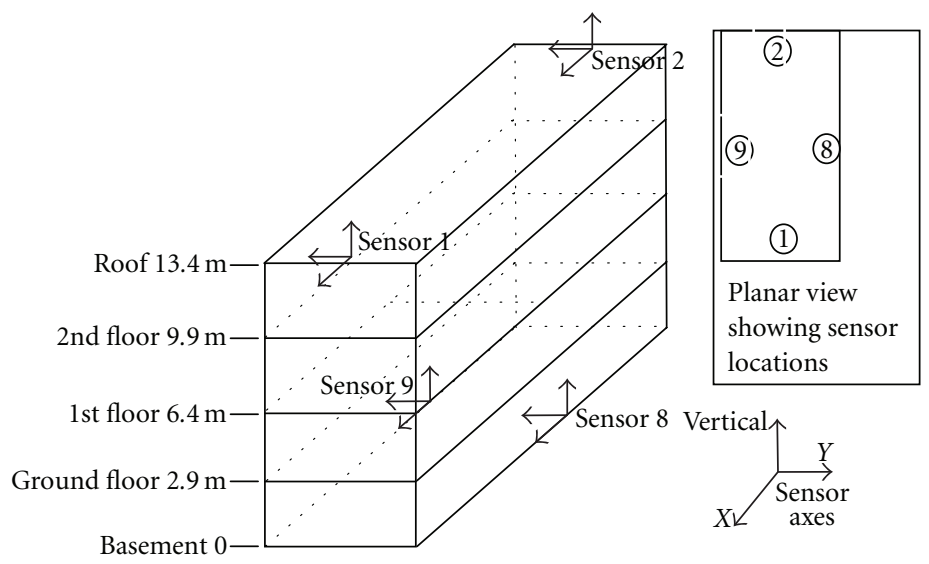

(b)

FIGURE 3: Building B: (a) typical floor plan showing location of stairs and (b) sensor array.

modal parameters in the so-called stabilization charts is often used: a range of system orders is tried and modal parameters which repeat themselves across that range are accepted as correct results. Stability tolerances are chosen based on the relative change in the modal properties, that is, modal frequencies, damping ratios, and mode shapes, of a given mode as the system order increases. For mode shapes stability, model assurance criterion (MAC) between the mode shapes of the present and previous orders were examined. MAC is an index that determines the similarity between two mode shapes. For modes $\phi_{i}$ and $\phi_{j}$, the MAC is defined as [23]

$$
\mathrm{MAC}=\frac{\left(\phi_{i}^{T} \phi_{j}\right)^{2}}{\left(\phi_{i}^{T} \phi_{i}\right)\left(\phi_{j}^{T} \phi_{j}\right)} .
$$

In (2), superscript $T$ denotes vector transpose.

3.3. System Identification for Evaluating SSI Effects. For evaluation of SSI effects using system identification procedures, Stewart and Fenves [12] proposed the following approach, based on earlier efforts by Veletsos and Nair [24] and Bielak [25] for surface and embedded foundations, respectively.
Consider structure shown in Figure 4. The height $h$ is the vertical distance from the base to the roof (or another measurement point located on the building). The symbols denoting translational displacements are as follows: $u_{g}$ for the free field translational displacement, $u_{f}$ for the foundation translational displacement with respect to the free field, and $u$ for the roof translational displacement with respect to the foundation. Foundation rocking angle is denoted by $\theta$, and its contribution to the roof translational displacement is $h \theta$. The Laplace domain counterparts of these quantities will be denotes as $\hat{u}_{g}, \hat{u}_{f}, \hat{u}$, and $\hat{\theta}$, respectively.

Stewart and Fenves [12] consider three different models and associated transfer functions $\left(H_{1}, H_{2}\right.$, and $\left.H_{3}\right)$ as follows.

(i) Flexible base model

$$
H_{1}=\frac{\left(\hat{u}_{g}+\hat{u}_{f}+\hat{u}+h \hat{\theta}\right)}{\hat{u}_{g}},
$$

where input is the free field displacement $u_{g}$ and output is the total roof displacement $u_{g}+u_{f}+u+h \theta$. 


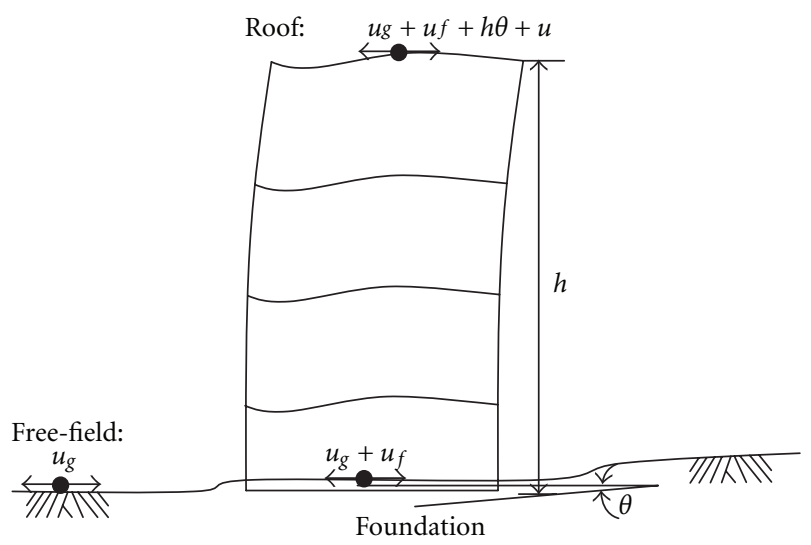

FIGURE 4: Inputs and outputs for evaluating SSI effects in system identification of buildings [12].

(ii) Pseudoflexible base model

$$
H_{2}=\frac{\hat{u}_{g}+\hat{u}_{f}+\hat{u}+h \hat{\theta}}{\hat{u}_{g}+\hat{u}_{f}},
$$

where input is the total foundation translational displacement $u_{g}+u_{f}$ and output is the total roof displacement $u_{g}+u_{f}+u+h \theta$.

(iii) Fixed base model

$$
H_{3}=\frac{\hat{u}_{g}+\hat{u}_{f}+\hat{u}+h \hat{\theta}}{\hat{u}_{g}+\hat{u}_{f}+h \hat{\theta}},
$$

where input is the total foundation displacement including rocking $u_{g}+u_{f}+h \theta$ and output is the total roof displacement $u_{g}+u_{f}+u+h \theta$.

The first two cases, that is, flexible base and pseudoflexible base are relevant for this study because of available measurements. The Stewart and Fenves model for pseudoflexible base summarized above is strictly applicable to the case a two degree of freedom (DOF) foundation where response of one of those DOFs (rocking) is not available. In the analysed case of a 3D building on multiple footing foundation there are clearly more DOFs as each footing will have six of them. We use the term "pseudoflexible base model" in a more general sense when at least some, but not all, of the foundation DOF responses are not available. Conversely, "fixed base model" would mean that all foundation DOF responses are available. It can be argued, however, that for short buildings, like the ones considered in this study, foundation rocking is not a dominant foundation response. Also, examination of the available translational foundation responses of buildings $\mathrm{A}$ and $\mathrm{B}$ shows that there is very small difference between horizontal responses of different footings due to the restraining effect of the tie beams joining them. Thus, we argue that in our case pseudoflexible base system identification results are similar to what would be fixed base results. Stewart and Fenves [12] demonstrate that the poles of the flexible base transfer function $H_{1}$ give natural frequencies and damping ratios of the entire dynamical system comprising the structure, foundation and soil. In other words, the identified modal parameters are influenced by the translational and rotational stiffness and damping of soil. The natural frequencies and damping ratios identified from the poles of the fixed base transfer function $\mathrm{H}_{3}$, on the other hand, depend on the properties of the structure alone. The pseudoflexible base case is an intermediate one where the poles of transfer function $\mathrm{H}_{2}$ yield modal parameters that depend on the stiffness and damping associated with the structure and foundation rocking (or more generally those foundation DOFs whose responses are ignored or not available). By comparing modal parameters identified from the different transfer functions the influence of the various types of foundation motions on those can be assessed.

To provide a simple quantification of the effects of SSI on the response of the building in this study, modal vibration parameters were sought through N4SID technique for the pseudoflexible base case and the flexible base case using input-output pairs consisting of a combination of free field, foundation, and superstructure level recordings as explained in (3)-(5). For building A, sensors 6 and 7 were taken as the inputs, while sensors 3,4 , and 5 as the outputs for the pseudoflexible base case, whereas sensor 10 (the free field sensor) as the input and sensors 3, 4, 5, 6, and 7 as the outputs for flexible base case. Likewise for building B, sensors 8 and 9 were taken as the inputs while sensors 1 and 2 as the outputs for the pseudoflexible base case, whereas sensor 10 as the input and sensors 1, 2, 8, and 9 as the outputs for flexible base case.

\section{Analyses of Seismic Response of the Buildings}

The objective of the research is to assess and understand the seismic response of buildings under a large number of earthquakes. In particular, trends are investigated between PGA and PRA, and then between PRA and the identified first three natural frequencies and corresponding damping ratios of the buildings using 50 earthquakes. The presentation will thus follow selection of earthquakes, correlating PGAs and 
TABLe 1: Maximum PGA and PRA recorded by individual sensors.

\begin{tabular}{lcc}
\hline Sensor & $\begin{array}{c}\text { Max. acceleration in } \\
X \text {-direction }(\mathrm{g})\end{array}$ & $\begin{array}{c}\text { Max. acceleration in } \\
Y \text {-direction }(\mathrm{g})\end{array}$ \\
\hline Free field & & \\
\hline 10 (PGA) & 0.0074 & 0.0138 \\
\hline Building A & & 0.0093 \\
\hline 6 (PGA) & 0.0059 & 0.0090 \\
7 (PGA) & 0.0061 & 0.040 \\
3 (PRA) & 0.019 & 0.041 \\
4 (PRA) & 0.021 & 0.0071 \\
\hline Building B & & 0.0076 \\
\hline (PGA) & 0.0071 & 0.025 \\
9 (PGA) & 0.0070 & 0.025 \\
1 (PRA) & 0.025 & \\
2 (PRA) & 0.030 & \\
\hline
\end{tabular}

PRAs from the free field and different points in the structure, modal system identification, correlating the PRAs with the identified frequencies and damping ratios for pseudoflexible and flexible base models, and evaluating the difference in the behaviour of buildings between pseudoflexible and flexible base models to assess the effects of SSI.

4.1. Earthquake Records Used in Analyses. For this study, 50 earthquakes recorded on the buildings which had epicentres within $200 \mathrm{~km}$ from the buildings were selected. The reason for adopting this was to select earthquakes of such an intensity which can excite the modes of interest with acceptable signal-to-noise ratios providing quality system identification results. The area surrounding the buildings had not been hit by any strong earthquake since their instrumentation. The majority, that is, 44 of the 50 recorded earthquakes, have a Richter magnitude ranging from 3 to 5 except only six that have more than 5 , with 5.2 being the maximum value. This means that nearly all of the earthquakes fall into the category of low intensity except a very few that can be treated as moderate events.

Table 1 summarizes maximum accelerations recorded at the free field, base and roof sensors for the 50 earthquakes. The maximum PGA at the free field sensor 10 was recorded along $Y$-direction $(0.0138 \mathrm{~g})$ and was almost double the maximum along $X$-direction $(0.0074 \mathrm{~g})$. The maximum PGA at the base of building $\mathrm{A}$ was $0.0093 \mathrm{~g}$ and was captured by sensor 6 along $Y$-direction and was a little higher than the maximum PGA recorded by sensor 7 along $Y$-direction $(0.0090 \mathrm{~g})$. Along the $X$-direction, sensor 7 recorded a little higher maximum PGA $(0.0061 \mathrm{~g})$ than sensor $6(0.0059 \mathrm{~g})$. For building B, the maximum PGA at the base was captured by sensor $9(0.0076 \mathrm{~g})$ along the $Y$-direction, while along the $X$-direction the maximum recorded PGA by sensor 9 was $0.0070 \mathrm{~g}$. For sensor 8 , the maximum recorded PGA was the same for both $X$ - and $Y$-directions $(0.0071 \mathrm{~g})$.

The maximum PRA of building A in the $Y$-direction was $0.041 \mathrm{~g}$ captured by sensor 4 , which was double the maximum recorded acceleration in the $X$-direction of $0.021 \mathrm{~g}$. For
TABLE 2: Amplification factors between PGA at the building base and PGA at the free field sensor.

\begin{tabular}{lccc}
\hline Sensors & Direction & Amplification factor & $R^{2}$ \\
\hline Building A & & & \\
\hline \multirow{2}{*}{ PGA 6 versus PGA 10 } & $X$ & 0.81 & 0.92 \\
& $Y$ & 0.55 & 0.82 \\
PGA 7 versus PGA 10 & $X$ & 0.83 & 0.92 \\
& $Y$ & 0.54 & 0.82 \\
\hline Building B & & & \\
\hline \multirow{2}{*}{ PGA 8 versus PGA 10 } & $X$ & 0.89 & 0.93 \\
& $Y$ & 0.45 & 0.88 \\
PGA 9 versus PGA 10 & $X$ & 0.90 & 0.93 \\
& $Y$ & 0.48 & 0.87 \\
\hline
\end{tabular}

sensor 3, the maximum PRA was almost the same $(0.040 \mathrm{~g})$ as that of sensor 4 along the $Y$-direction and almost double the maximum PRA acceleration in the $X$-direction $(0.019 \mathrm{~g})$. For building $\mathrm{B}$, the maximum recorded PRA was in the $X$ direction $(0.030 \mathrm{~g})$ and was captured by sensor 2 . This was only a little higher than maximum PRA in the $Y$-direction $(0.025 \mathrm{~g})$. For sensor 1 , the maximum PRA was $0.025 \mathrm{~g}$ and was the same for both $X$ - and $Y$-directions. It should be noted, however, that the majority ( $94 \%$ and $96 \%$, resp.) of analysed earthquakes resulted in PRAs below either $0.015 \mathrm{~g}$ or $0.01 \mathrm{~g}$ for building $\mathrm{A}$ and $\mathrm{B}$, respectively (this will also be seen clearly later in Figures 5-8 and 11-18).

\subsection{Correlations between Free Field PGA and Building Base} PGA and between Building Base PGA and PRA. The first analysis is concerned with amplification factors between maximum accelerations recorded by different sensors. In this study, the amplification factor is defined as the linear regression coefficient [26] between the maximum absolute accelerations in either $X$ - or $Y$-direction recorded by the two sensors at hand calculated over the 50 considered earthquake records.

Table 2 summarizes all the amplification factors between the four sensors located at the base of both buildings and the free field sensor 10. Figures 5 and 6 show, as examples, scatter plots of PGAs of base sensor 6 and 8 versus PGAs of the free field sensor 10 for $X$ - and $Y$-directions for building $A$ and $B$, respectively. As can be seen from Table 2, all the amplification factors are smaller than 1 , indicating that PGAs of foundations were generally smaller than those of the free field. Also, the amplification factors for two sensors installed in the same building do not differ significantly (when the same direction is concerned). For both buildings, the amplification factors in the $X$-direction were generally significantly larger than in the $Y$-direction. The largest value of the amplification factor, 0.90 , was for sensor 9 located in building B in $X$-direction; the smallest, 0.45 , for sensor 8 located in the same building in the $Y$-direction. For building $\mathrm{A}$, those maximum and minimum values were of the same order, 0.83 and 0.55 , respectively. The values of $R^{2}$, or coefficient of determination [27], also reported in 


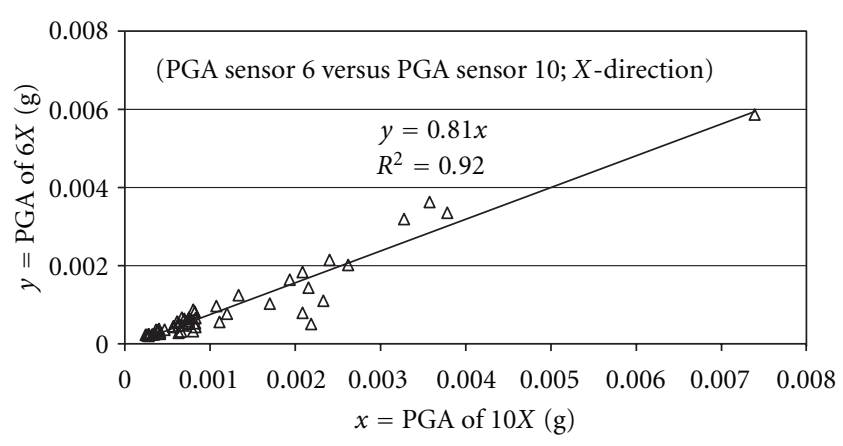

(a)

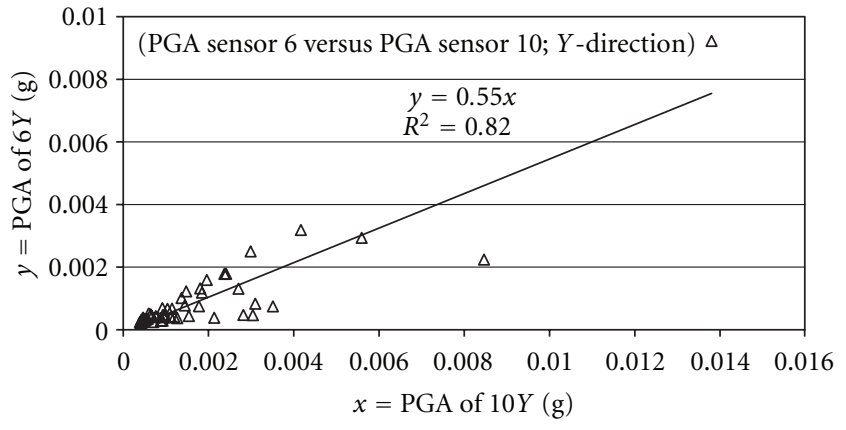

(b)

FIGURe 5: PGA at base of building A recorded by sensor 6 versus PGA at free field recorded by sensor 10: (a) $X$-direction and (b) $Y$-direction.

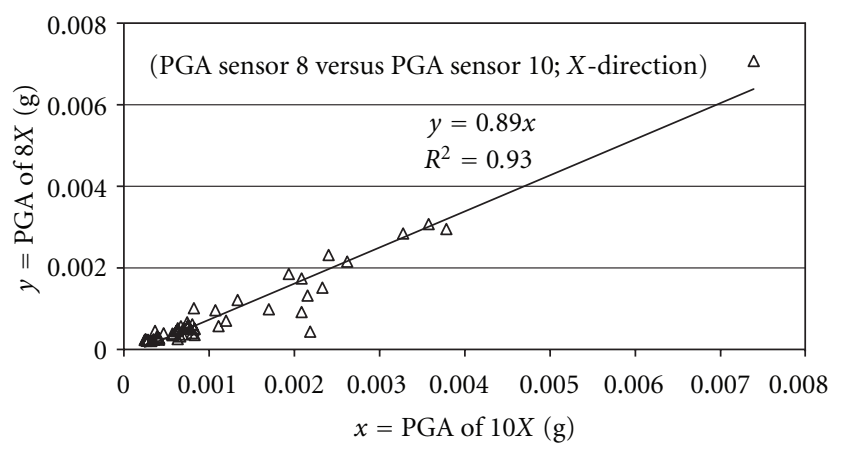

(a)

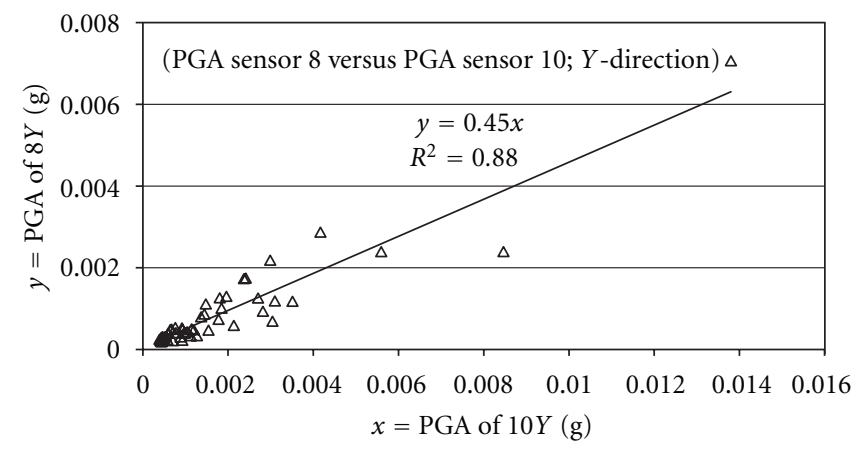

(b)

FIGURE 6: PGA at base of building B recorded by sensor 8 versus PGA at free field recorded by sensor 10: (a) X-direction and (b) Y-direction.

Table 2 vary between 0.82 and 0.93 indicating strong linear dependence between the analysed variables. This strong correlation is also evident in Figures 5 and 6. (What is considered strong, reasonable, or weak correlation based on $R^{2}$ values depends on the context; in this research it was decided that $R^{2}>0.8$ denotes strong or good correlation, $R^{2}>0.5$ reasonable correlation, and $R^{2}>0.25$ weak but still perceivable correlation. Those thresholds are not to be understood as "hard.")

A similar study was conducted for the amplification factors between PRAs of the roof sensors and PGAs of the base sensors, and Table 3 summarizes the results. Figures 7 and 8 again show examples of scatter plots of PRAs of roof sensor 4 versus PGAs of base sensors 6, and PRAs of roof sensor 1 versus PGAs of base sensors 8, respectively. For building $\mathrm{A}$, it can be seen that larger amplification factors, varying between 4.20 and 4.44 occurred in $Y$-direction, while for $X$-direction they were between 3.16 and 3.37. These ranges of amplification factors also show that there were only small differences between different sensor pairs for a given direction, $X$ or $Y$. For building $\mathrm{B}$, the amplification factors for $X$ - and $Y$-direction were generally much more uniform compared to building $\mathrm{A}$, and they did not differ
TABle 3: Amplification factors between PRA at the roof and PGA at the building base.

\begin{tabular}{lccc}
\hline Sensors & Direction & Amplification factor & $R^{2}$ \\
\hline Building A & & & \\
\hline PRA 3 versus PGA 6 & $X$ & 3.37 & 0.80 \\
& $Y$ & 4.20 & 0.96 \\
PRA 3 versus PGA 7 & $X$ & 3.31 & 0.79 \\
& $Y$ & 4.26 & 0.96 \\
PRA 4 versus PGA 6 & $X$ & 3.21 & 0.85 \\
& $Y$ & 4.39 & 0.95 \\
PRA 4 versus PGA 7 & $X$ & 3.16 & 0.85 \\
& $Y$ & 4.44 & 0.95 \\
\hline Building B & & & \\
\hline \multirow{2}{*}{ PRA 1 versus PGA 8 } & $X$ & 3.29 & 0.93 \\
PRA 1 versus PGA 9 & $Y$ & 3.51 & 0.94 \\
PRA 2 versus PGA 8 & $X$ & 3.22 & 0.91 \\
& $Y$ & 3.27 & 0.90 \\
PRA 2 versus PGA 9 & $X$ & 3.87 & 0.90 \\
& $Y$ & 3.52 & 0.97 \\
\end{tabular}




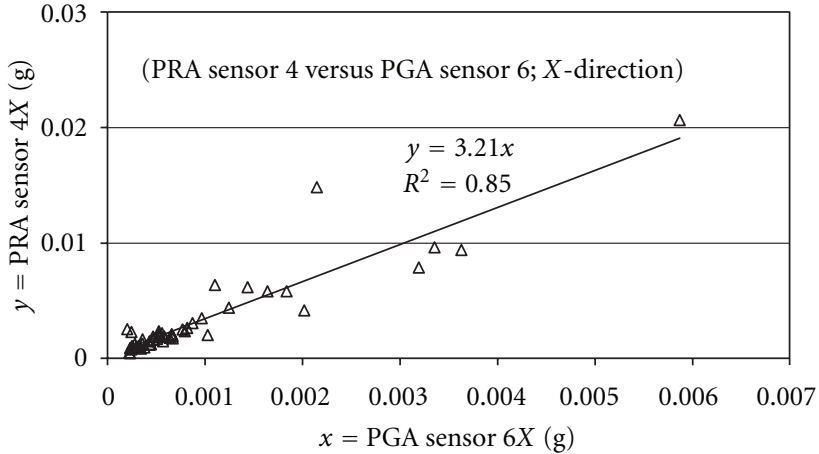

(a)

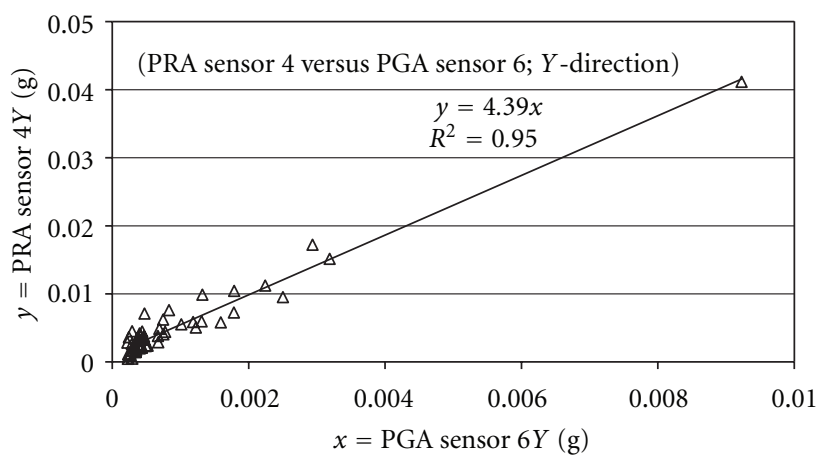

(b)

FIgURe 7: PRA of building A recorded by sensor 4 versus PGA at base recorded by sensor 6: (a) X-direction and (b) $Y$-direction.

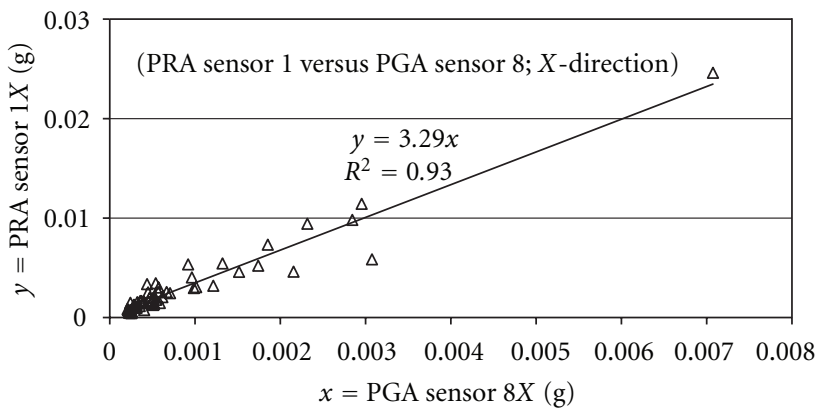

(a)

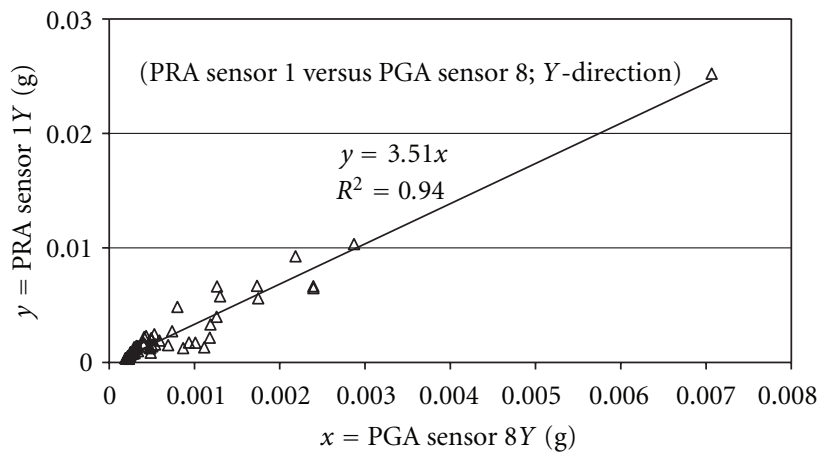

(b)

FIGURE 8: PRA of building B recorded by sensor 1 versus PGA at base recorded by sensor 8: (a) X-direction and (b) $Y$-direction.

significantly between the different sensor pairs. The ranges of amplification factors were between 3.22 and 3.87, and between 3.27 and 3.52 for $X$ - and $Y$-direction, respectively. The values of $R^{2}$ in Table 3 vary between 0.79 and 0.97 again confirming strong linear dependence of respective PRAs of PGAs. This is also evident in Figures 7 and 8.

4.3. Modal Identification of the Instrumented Buildings. The second analysis reported in this paper uses the same 50 earthquake records and performs system identification of modal parameters of the two buildings. The identified natural frequencies and damping ratios are plotted against PRAs and their trends are statistically evaluated. N4SID technique was used to identify the first three frequencies, corresponding damping ratios, and mode shapes. Sampling rate of the digitized signal was $200 \mathrm{~Hz}$ and for establishing stabilization charts system orders from 2 to 200 were considered. A typical stabilization chart is shown in Figure 9: the marker "black dot" shows all the identified frequencies, "red dot" shows stable frequencies and damping ratios, while "blue circle" stable frequencies, damping ratios, and mode shapes. In this research, an identified frequency was considered to be stable if the absolute deviation between the frequency identified at the present and previous order was less than or equal to $0.01 \mathrm{~Hz}$. A stable damping ratio was defined by an absolute deviation less than 5\%. For mode shapes stability, model assurance criterion (MAC) between the mode shapes of the present and previous orders was to be at least $90 \%$ or greater. It can be seen in Figure 9 that three modes can be identified with confidence and subsequent discussions focus on these.

For both pseudoflexible and flexible base models same mode shapes were observed in the planar view. The typical first three mode shapes of building $A$ are shown in Figure 10(a) in planar view. (Note that because of a limited number of measurement points those graphs assume the floors were rigid diaphragms.) The shape of the first mode shows it to be a translational mode along $X$-direction with some torsion. The second mode is nearly purely torsional and the third one is a translation dominant along $Y$ direction coupled with torsion. Building B has very similar shapes for the first three modes (Figure 10(b)). Structural irregularities, such as those due to the internal longitudinal beams being not in the middle for both buildings and the shear core present near the North end of building A, create unsymmetrical distribution of stiffness which has caused the modes to be coupled translational-torsional. Another plausible source of mode shape coupling is varying soil stiffness under different foundations and around different parts of the buildings. 


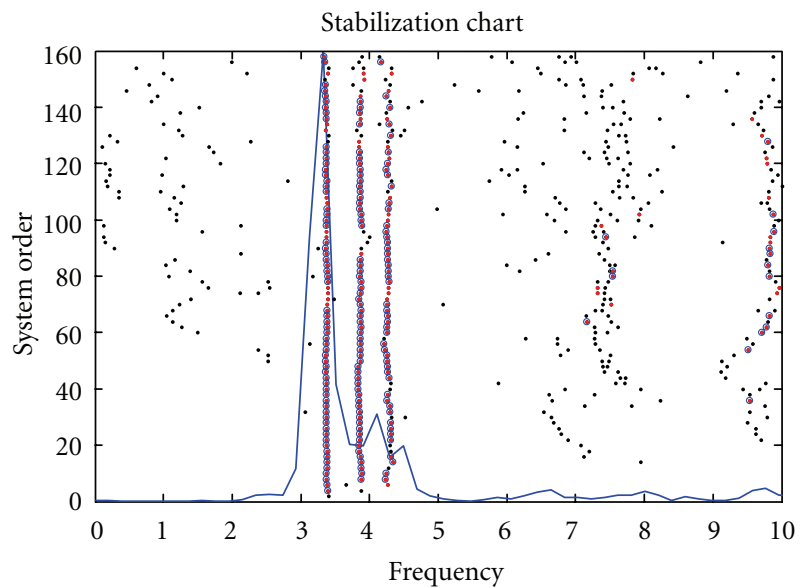

Figure 9: Typical stabilization chart showing stable modes (superimposed by power spectral density curve).

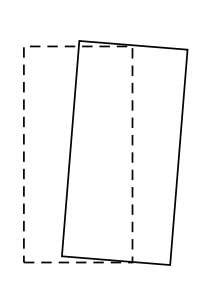

1st mode shape

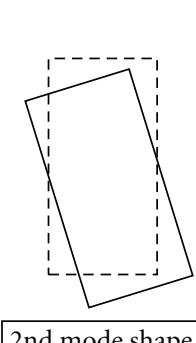

2nd mode shape
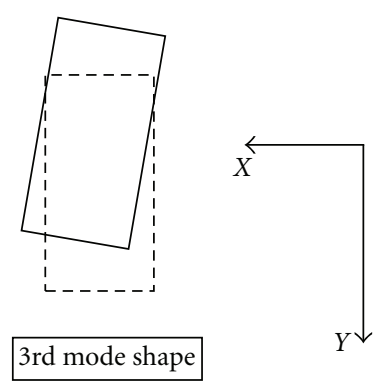

(a)

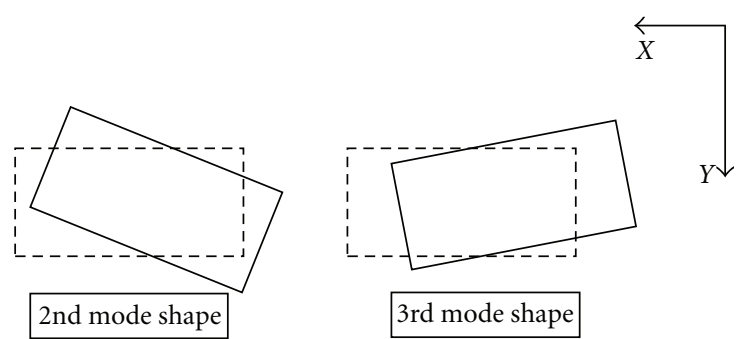

(b)

FIgURE 10: Planar views of the first three mode shapes: (a) building A and (b) building B.

During some events, the first, second, or third mode or any two of them were missing in the system identification results, which suggests that during those particular events these modes did not vibrate strongly enough. In some events, the second and third modal frequencies tended to be very close and the minimum difference between these two was found to be $0.03 \mathrm{~Hz}$. This shows the capability of N4SID technique to identify very closely spaced modes.

4.3.1. Modal Frequency Identification Results and Their Dependence on PRA. Table 4 shows the minimum, maximum, average, and percentage change (= (maximum minimum)/average $\times 100 \%$ ) values of the identified modal frequencies for the analysed 50 earthquakes for both pseudoflexible and flexible base models. The average first three modal frequencies for building A were $3.37 \mathrm{~Hz}, 3.67 \mathrm{~Hz}$, and $3.80 \mathrm{~Hz}$ for the pseudoflexible base model, and $3.33 \mathrm{~Hz}$, $3.61 \mathrm{~Hz}$, and $3.79 \mathrm{~Hz}$ for the flexible base model. For building $\mathrm{B}$ these were $3.33 \mathrm{~Hz}, 3.80 \mathrm{~Hz}$, and $4.14 \mathrm{~Hz}$ for the pseudoflexible base model, and $3.28 \mathrm{~Hz}, 3.79 \mathrm{~Hz}$, and $4.11 \mathrm{~Hz}$ for the flexible base model. For pseudoflexible base models, the percentage change for the selected 50 events in the first, second, and third modal frequencies is $13 \%, 14 \%$, and $9 \%$, respectively, for building $\mathrm{A}$, whereas for building $\mathrm{B}$ it is $22 \%, 21 \%$, and $27 \%$, respectively. For flexible base models, the percentage changes in the first three frequencies are $14 \%, 19 \%$, and $11 \%$ respectively for building $\mathrm{A}$, whereas for building B they are $20 \%, 25 \%$, and $29 \%$, respectively.

It is of interest to explore whether, and if so how, those changes in frequencies correlate with response magnitude. Figures 11-14 show the results of modal frequency identification for the analysed 50 earthquakes. In each figure, 


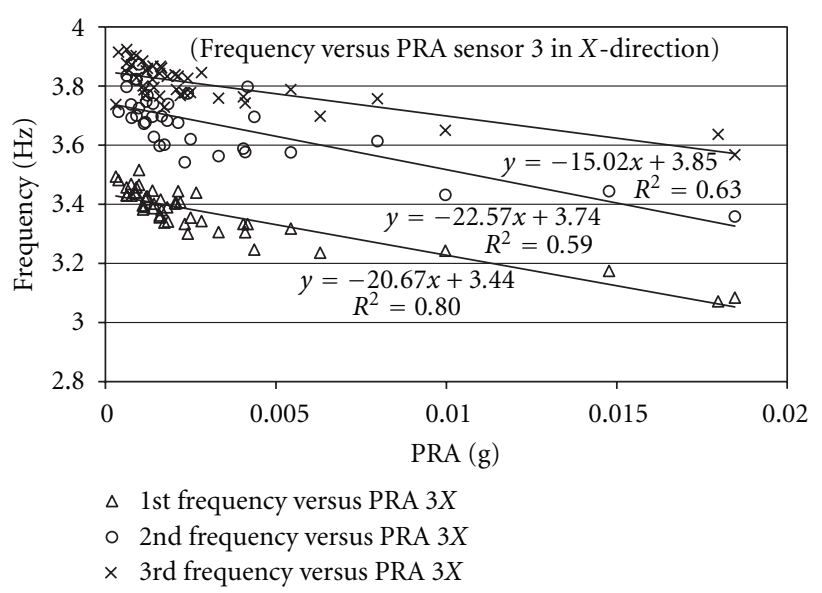

(a)

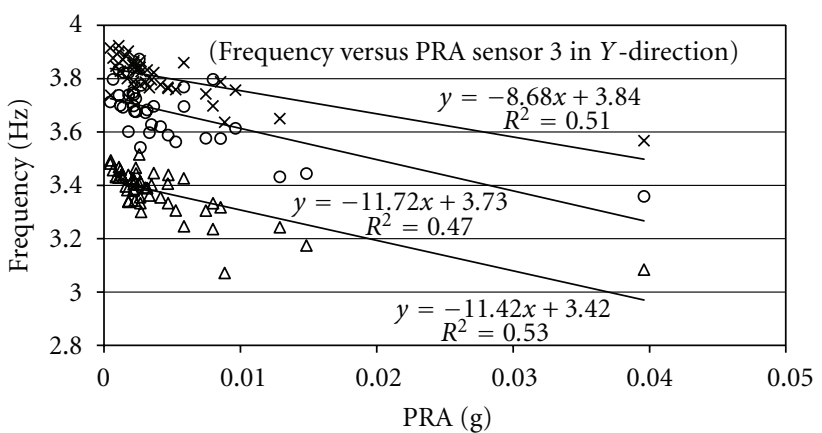

$\triangle 1$ st frequency versus PRA $3 Y$

- 2nd frequency versus PRA $3 Y$

$\times$ 3rd frequency versus PRA $3 Y$

(b)

Figure 11: First three modal frequencies of building A for pseudoflexible base case versus PRA of sensor 3: (a) X-direction and (b) $Y$ direction.

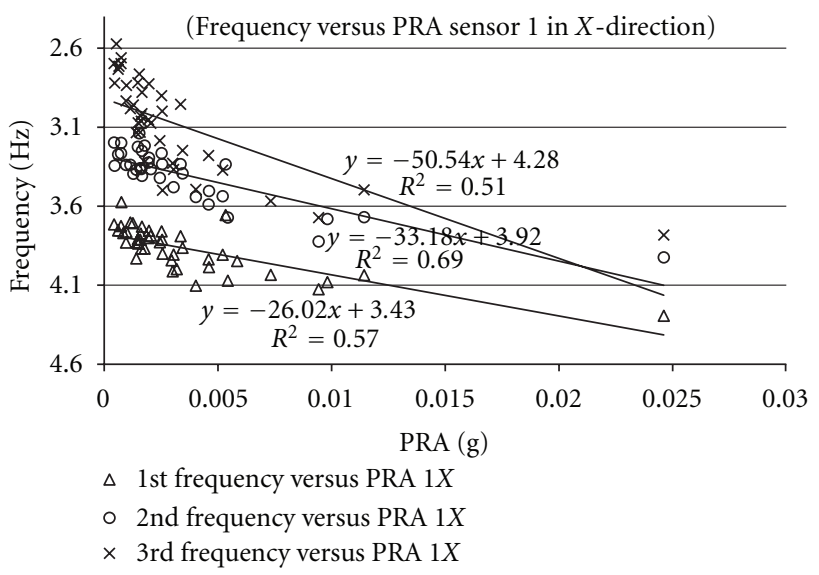

(a)

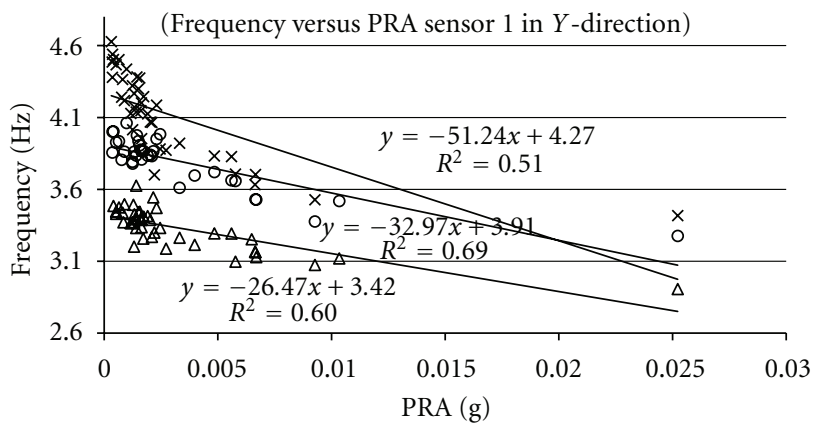

$\Delta$ 1st frequency versus PRA $1 Y$

- 2nd frequency versus PRA $1 Y$

$\times$ 3rd frequency versus PRA $1 Y$

(b)

FIGURE 12: First three modal frequencies of building B for pseudoflexible base case versus PRA of sensor 1: (a) $X$-direction and (b) $Y$ direction.

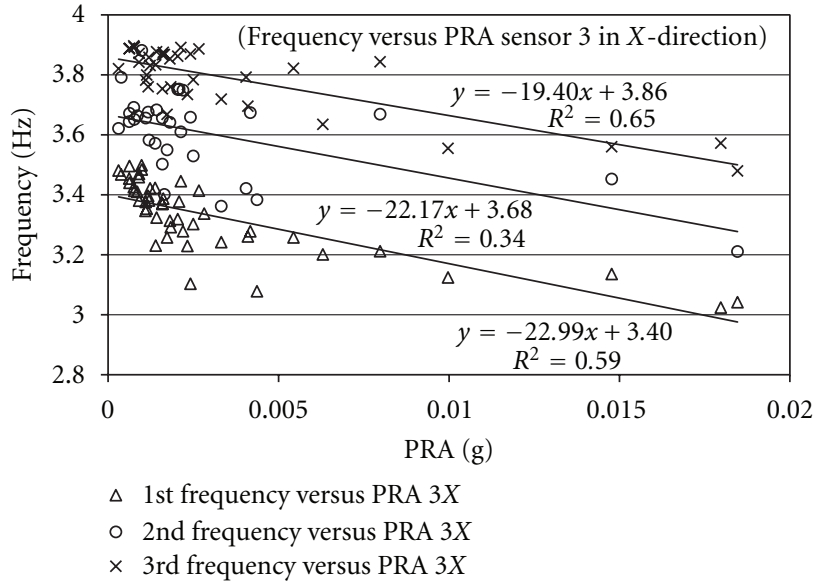

(a)

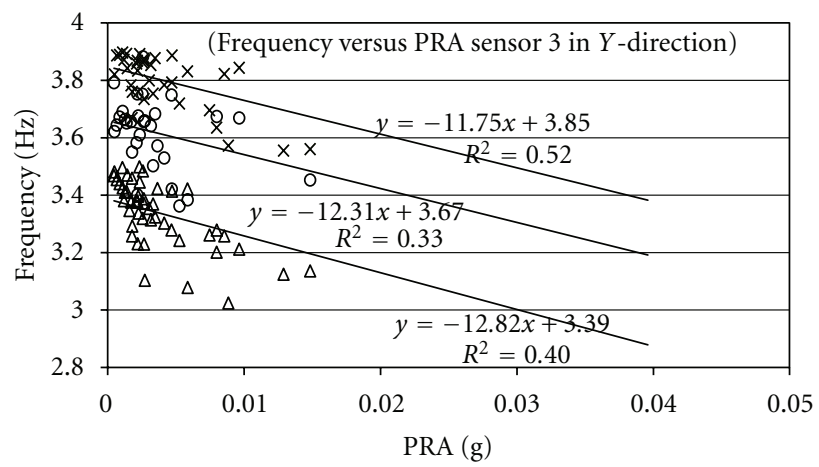

$\triangle 1$ st frequency versus PRA $3 Y$

$\circ$ 2nd frequency versus PRA $3 Y$

$\times$ 3rd frequency versus PRA $3 Y$

(b)

FIGURE 13: First three modal frequencies of building A for flexible base case versus PRA of sensor 3: (a) X-direction and (b) Y-direction. 
TABLE 4: Summary of identified frequencies for buildings A and B for pseudoflexible and flexible base models.

\begin{tabular}{|c|c|c|c|c|c|c|c|c|c|}
\hline \multirow[t]{2}{*}{ Building } & \multirow[t]{2}{*}{ Mode } & \multicolumn{4}{|c|}{$\begin{array}{c}\text { Pseudoflexible base } \\
\text { Frequency }(\mathrm{Hz})\end{array}$} & \multicolumn{4}{|c|}{$\begin{array}{c}\text { Flexible base } \\
\text { Frequency }(\mathrm{Hz})\end{array}$} \\
\hline & & Min. & Max. & Avg. & $\%$ change & Min. & Max. & Avg. & $\%$ change \\
\hline \multirow{3}{*}{ Building A } & $1 \mathrm{st}$ & 3.07 & 3.52 & 3.37 & $13 \%$ & 3.02 & 3.50 & 3.33 & $14 \%$ \\
\hline & $2 \mathrm{nd}$ & 3.36 & 3.87 & 3.67 & $14 \%$ & 3.21 & 3.88 & 3.61 & $19 \%$ \\
\hline & $3 r d$ & 3.57 & 3.92 & 3.80 & $9 \%$ & 3.48 & 3.90 & 3.79 & $11 \%$ \\
\hline \multirow{3}{*}{ Building B } & $1 \mathrm{st}$ & 2.91 & 3.63 & 3.33 & $22 \%$ & 2.85 & 3.51 & 3.28 & $20 \%$ \\
\hline & 2 nd & 3.28 & 4.06 & 3.80 & $21 \%$ & 3.22 & 4.16 & 3.79 & $25 \%$ \\
\hline & $3 \mathrm{rd}$ & 3.53 & 4.63 & 4.14 & $27 \%$ & 3.44 & 4.62 & 4.11 & $29 \%$ \\
\hline
\end{tabular}

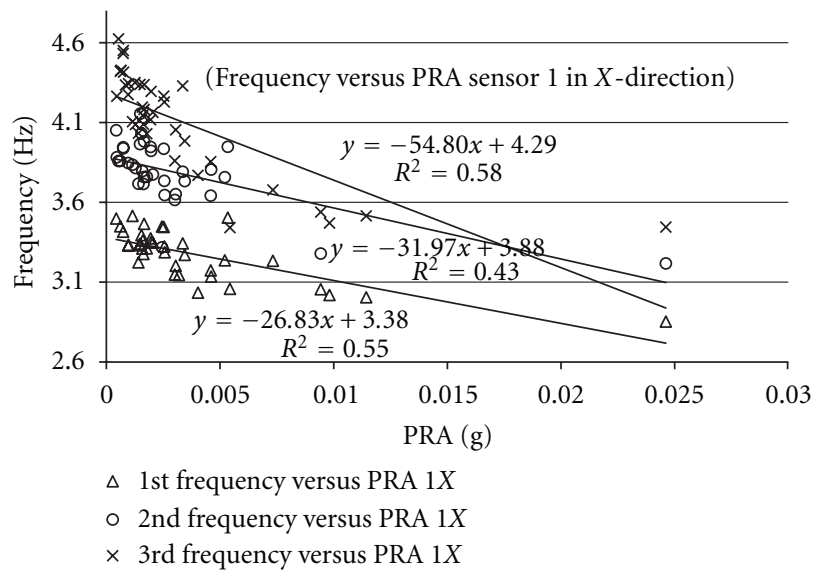

(a)

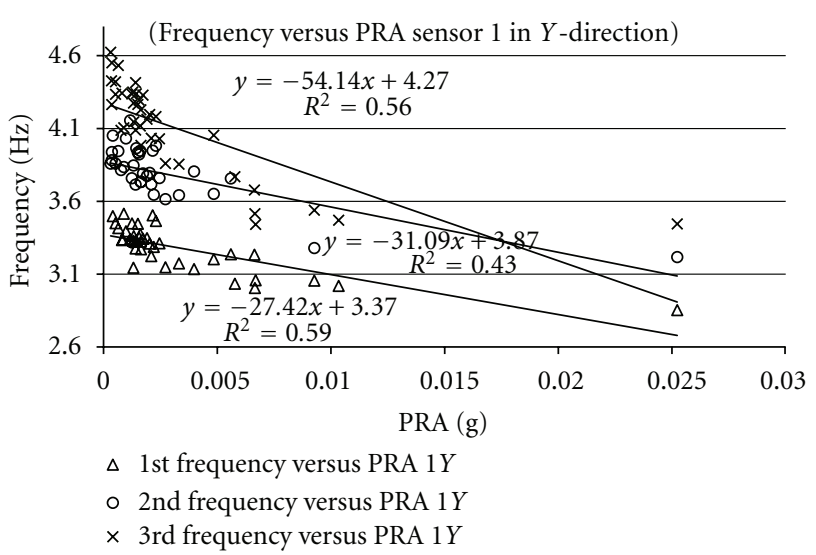

(b)

FIGURE 14: First three modal frequencies of building B for flexible base case versus PRA of sensor 1: (a) X-direction and (b) Y-direction.

those frequencies are plotted against PRAs in either $X$ - or $Y$ direction of a representative roof sensor, being sensor 3 for building A and sensor 1 for building B. Figures 11 and 12 are for pseudoflexible base models, and Figures 13 and 14 are for flexible base models, respectively. In Figures 11-14 it can clearly be seen that modal frequencies decrease as the PRAs increase and this is observed for both buildings, in all three modes, and along both $X$ - and $Y$-directions.

In order to quantify relationships between PRAs and modal frequencies linear regression [26] was applied. The results of the linear regression analysis are summarized in Table 5, where formulas relating the identified modal frequencies and PRA in both $X$ - and $Y$-direction are listed. The negative values of the linear terms confirm again the decreasing trend of modal frequencies with increasing PRA. The strength of correlations of the variables is illustrated by $R^{2}$ coefficients. These vary from 0.33 to 0.80 indicating that a linear relationship fits the data to a reasonable and/or sometimes good degree. Had more data with PRAs in the range beyond $0.01 \mathrm{~g}$ been available it would have helped to develop more refined relationship than the linear one.

\subsubsection{Modal Damping Ratio Identification Results and Their} Dependence on PRA. Table 6 shows the minimum, maximum, average, and percentage change (= (maximum minimum)/average $\times 100 \%$ ) values of the identified modal damping ratios for the analysed 50 earthquakes for both pseudoflexible and flexible base models. For the pseudoflexible base models, the average values of damping ratios for the first, second, and third modes were $2.7 \%, 4.3 \%$, and $2.9 \%$, respectively, for building $\mathrm{A}$, and $2.9 \%, 4.5 \%$, and $5.6 \%$, respectively, for building $\mathrm{B}$, whereas for the flexible base models these were $3.4 \%, 5.6 \%$, and $3.1 \%$ for building $\mathrm{A}$, and $3.3 \%, 4.6 \%$, and $5.7 \%$ for building $\mathrm{B}$, respectively. It can be noticed that the identified damping ratios show considerable scatter for both buildings - the percentage changes were between $135 \%$ and $240 \%$.

Figures 15-18 show the results of modal damping ratio identification for the analysed 50 earthquakes. Like the modal frequencies previously, the damping ratios are plotted against PRAs in either $X$ - or $Y$-direction of sensor 3 for building A and sensor 1 for building B, respectively. Figures 15 and 16 are for pseudoflexible base models and Figures 17 and 18 are for flexible base models, respectively. The initial observation about considerable scatter of results, mentioned while analysing Table 6, is now clearly revealed in the figures. With the exception of the first mode for building $\mathrm{A}$ for the pseudoflexible base case and building $\mathrm{B}$ for both pseudoflexible and flexible base cases (Figures 15(a), 15(d); 16(a), 16(d); 18(a), 18(d)), where an increasing trend was noticeable, no clear trends in damping ratios could be discerned. Logarithmic curves were fitted to the damping 
TABLE 5: Dependence of modal frequencies on PRA.

\begin{tabular}{|c|c|c|c|c|}
\hline Mode & Direction & Model type & $\begin{array}{l}\text { Modal frequency }(y)-\text { PRA } \\
\left.(x) \text { relationship }{ }^{*}\right)\end{array}$ & $R^{2}$ \\
\hline \multicolumn{5}{|c|}{ Building A } \\
\hline \multirow{4}{*}{1 st } & \multirow{2}{*}{$X$} & P/flexible base ${ }^{(*)}$ & $y=-20.67 x+3.44$ & 0.80 \\
\hline & & Flexible base & $y=-22.99 x+3.40$ & 0.59 \\
\hline & \multirow{2}{*}{ Y } & $\mathrm{P} /$ flexible base & $y=-11.42 x+3.42$ & 0.53 \\
\hline & & Flexible base & $y=-12.82 x+3.39$ & 0.40 \\
\hline \multirow{4}{*}{2 nd } & \multirow{2}{*}{$X$} & $\mathrm{P} /$ flexible base & $y=-22.57 x+3.74$ & 0.59 \\
\hline & & Flexible base & $y=-22.17 x+3.68$ & 0.34 \\
\hline & \multirow{2}{*}{ Y } & $\mathrm{P} /$ flexible base & $y=-11.72 x+3.73$ & 0.47 \\
\hline & & Flexible base & $y=-12.31 x+3.67$ & 0.33 \\
\hline \multirow{4}{*}{$3 r d$} & \multirow{2}{*}{$X$} & $\mathrm{P} /$ flexible base & $y=-15.02 x+3.85$ & 0.63 \\
\hline & & Flexible base & $y=-19.40 x+3.86$ & 0.65 \\
\hline & \multirow{2}{*}{ Y } & $\mathrm{P} /$ flexible base & $y=-8.68 x+3.84$ & 0.51 \\
\hline & & Flexible base & $y=-11.75 x+3.85$ & 0.52 \\
\hline \multicolumn{5}{|c|}{ Building B } \\
\hline \multirow{4}{*}{1 st } & \multirow{2}{*}{$X$} & $\mathrm{P} /$ flexible base & $y=-26.02 x+3.43$ & 0.57 \\
\hline & & Flexible base & $y=-26.83 x+3.38$ & 0.55 \\
\hline & \multirow{2}{*}{ Y } & $\mathrm{P} /$ flexible base & $y=-26.47 x+3.42$ & 0.60 \\
\hline & & Flexible base & $y=-27.42 x+3.37$ & 0.59 \\
\hline \multirow{4}{*}{$2 \mathrm{nd}$} & \multirow{2}{*}{$X$} & $\mathrm{P} /$ flexible base & $y=-33.18 x+3.92$ & 0.69 \\
\hline & & Flexible base & $y=-31.97 x+3.88$ & 0.43 \\
\hline & \multirow{2}{*}{ Y } & $\mathrm{P} /$ flexible base & $y=-32.97 x+3.91$ & 0.69 \\
\hline & & Flexible base & $y=-31.09 x+3.87$ & 0.43 \\
\hline \multirow{4}{*}{$3 \mathrm{rd}$} & \multirow{2}{*}{$X$} & $\mathrm{P} /$ flexible base & $y=-50.54 x+4.28$ & 0.51 \\
\hline & & Flexible base & $y=-54.80 x+4.29$ & 0.58 \\
\hline & \multirow{2}{*}{ Y } & $\mathrm{P} /$ flexible base & $y=-51.24 x+4.27$ & 0.51 \\
\hline & & Flexible base & $y=-54.14 x+4.27$ & 0.56 \\
\hline
\end{tabular}

${ }^{(*)}$ Modal frequency in units of $\mathrm{Hz}$, PRA in units of g.

${ }^{(* *)} \mathrm{P} /$ flexible base $=$ pseudoflexible base.

TABLE 6: Summary of identified damping ratios for buildings A and B for pseudoflexible and flexible base models.

\begin{tabular}{|c|c|c|c|c|c|c|c|c|c|}
\hline \multirow[t]{2}{*}{ Building } & \multirow{2}{*}{ Mode } & \multicolumn{4}{|c|}{$\begin{array}{l}\text { Pseudoflexible base } \\
\text { Damping ratio (\%) }\end{array}$} & \multicolumn{4}{|c|}{$\begin{array}{c}\text { Flexible base } \\
\text { Damping ratio }(\%)\end{array}$} \\
\hline & & Min. & Max. & Avg. & $\%$ change & Min. & Max. & Avg. & $\%$ change \\
\hline \multirow{3}{*}{ Building A } & 1 st & 0.6 & 4.3 & 2.7 & $138 \%$ & 1.2 & 7.3 & 3.4 & $176 \%$ \\
\hline & 2nd & 0.5 & 6.6 & 4.3 & $151 \%$ & 1.4 & 12.1 & 5.6 & $190 \%$ \\
\hline & $3 r d$ & 1.0 & 7.3 & 2.9 & $217 \%$ & 1.0 & 8.3 & 3.1 & $240 \%$ \\
\hline \multirow{3}{*}{ Building B } & $1 \mathrm{st}$ & 0.5 & 4.9 & 2.9 & $155 \%$ & 0.8 & 5.4 & 3.3 & $140 \%$ \\
\hline & $2 \mathrm{nd}$ & 1.8 & 7.9 & 4.5 & $135 \%$ & 2.3 & 9.4 & 4.6 & $154 \%$ \\
\hline & $3 r d$ & 1.2 & 10.0 & 5.6 & $158 \%$ & 1.6 & 12.4 & 5.7 & $190 \%$ \\
\hline
\end{tabular}

ratios of the first mode for the three aforementioned cases where a trend could be inferred. These curves are included in Figures 15(a), 15(d), 16(a), 16(d), and 18(a), 18(d), while their $R^{2}$ values are from 0.27 to 0.59 showing between a weak and up to a reasonable fit.
4.4. Evaluation of SSI Effects. The section reexamines the system identification results from the point of view of assessing SSI effects. From Table 4, the average first, second, and third frequencies for building A are $3.37 \mathrm{~Hz}, 3.67 \mathrm{~Hz}$, and $3.80 \mathrm{~Hz}$, respectively, for pseudoflexible base models, whereas for 


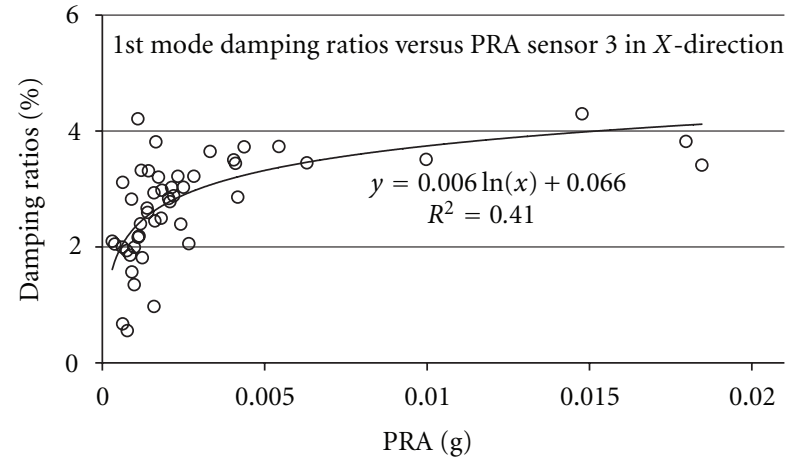

(a)

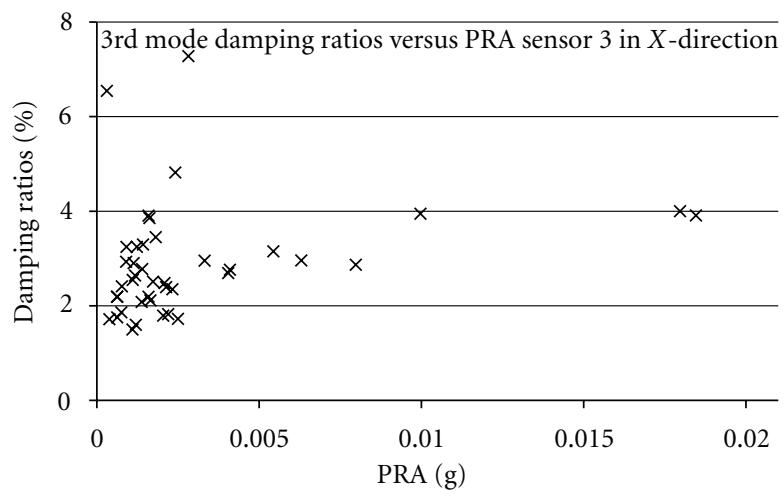

(c)

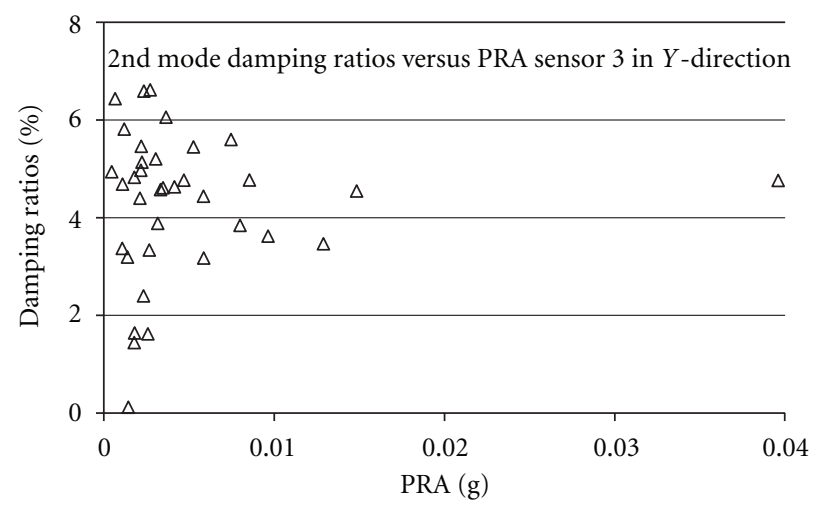

(e)

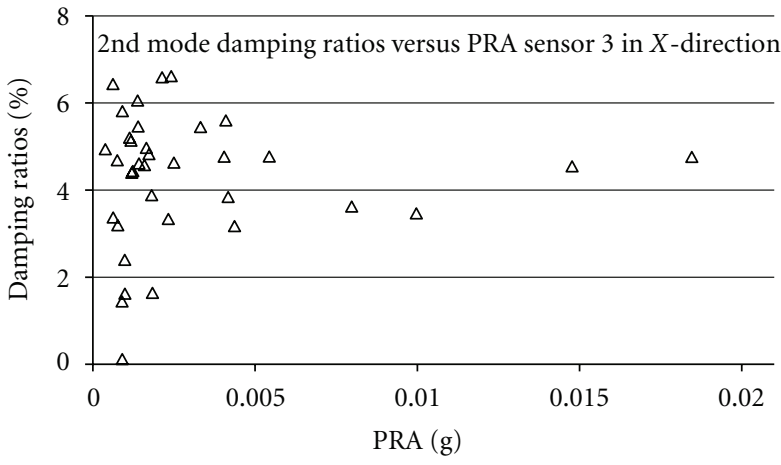

(b)

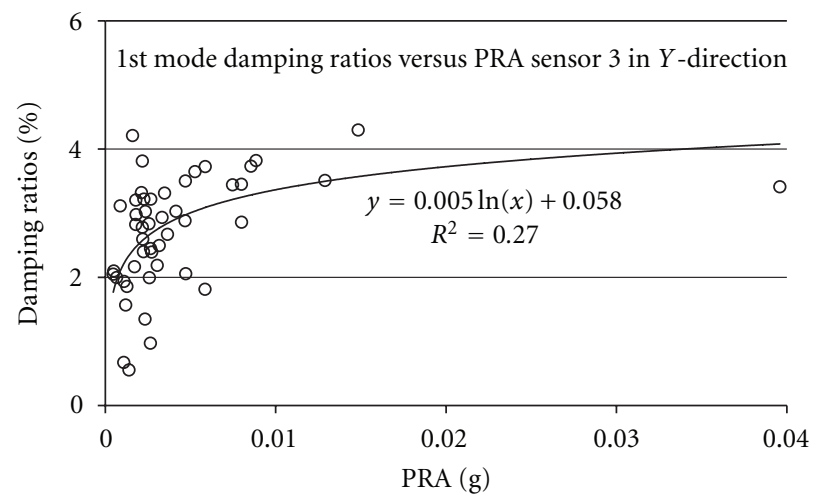

(d)

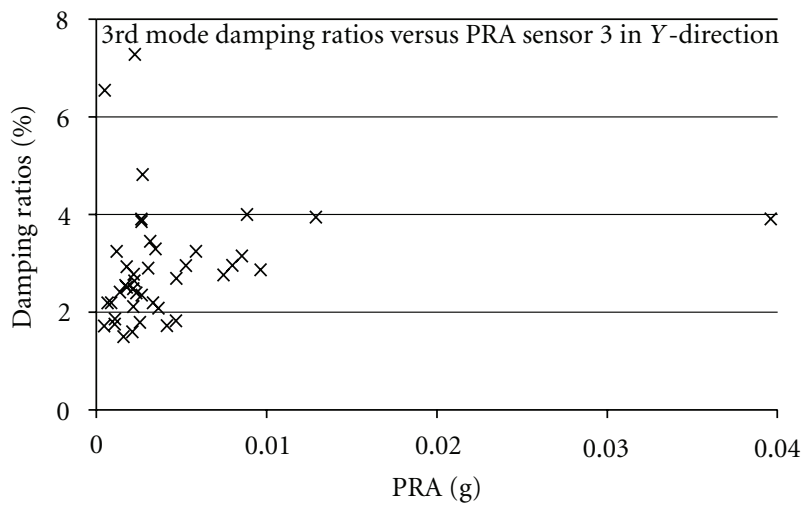

(f)

Figure 15: Modal damping ratios of building A for pseudoflexible base case: (a) 1st mode, (b) 2nd mode, (c) 3rd mode versus X-direction PRA of sensor 3; (d) 1st mode, (e) 2nd mode, and (f) 3rd mode versus $Y$-direction PRA of sensor 3.

flexible base models the average first three frequencies are $3.33 \mathrm{~Hz}, 3.61 \mathrm{~Hz}$, and $3.79 \mathrm{~Hz}$. Thus, the flexible base model frequencies are lower by $1.2 \%, 1.6 \%$, and $0.3 \%$, respectively, compared to the pseudoflexible base model frequencies. For building $\mathrm{B}$, the average first three frequencies are $3.33 \mathrm{~Hz}$, $3.80 \mathrm{~Hz}$, and $4.14 \mathrm{~Hz}$ for the pseudoflexible base models, whereas for the flexible base models these are $3.28 \mathrm{~Hz}$,
$3.79 \mathrm{~Hz}$, and $4.11 \mathrm{~Hz}$. Again, the flexible based frequencies are lower, this time by $1.5 \%, 0.3 \%$, and $0.7 \%$, respectively, compared to the pseudoflexible base model frequencies. The average damping ratios (Table 6) observed for the flexible base models are larger as compared to the pseudoflexible base models. The average values are respectively: for building $\mathrm{A}$, $2.7 \%, 4.3 \%$, and $2.9 \%$ for the pseudoflexible base case and 


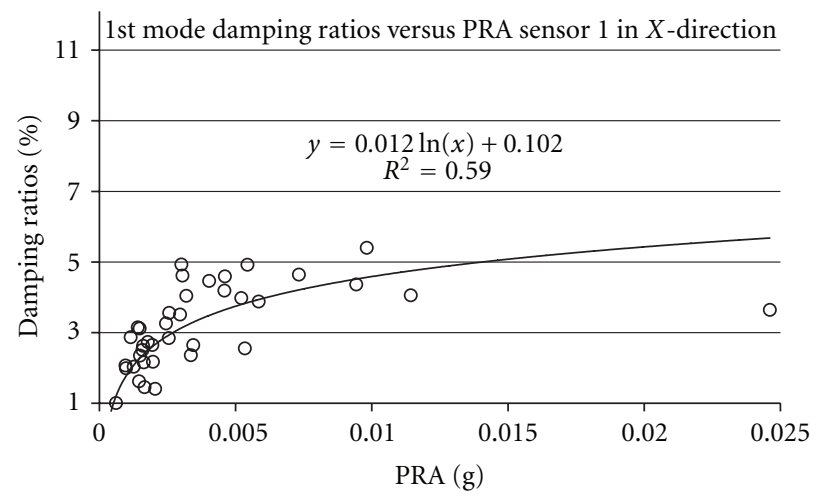

(a)

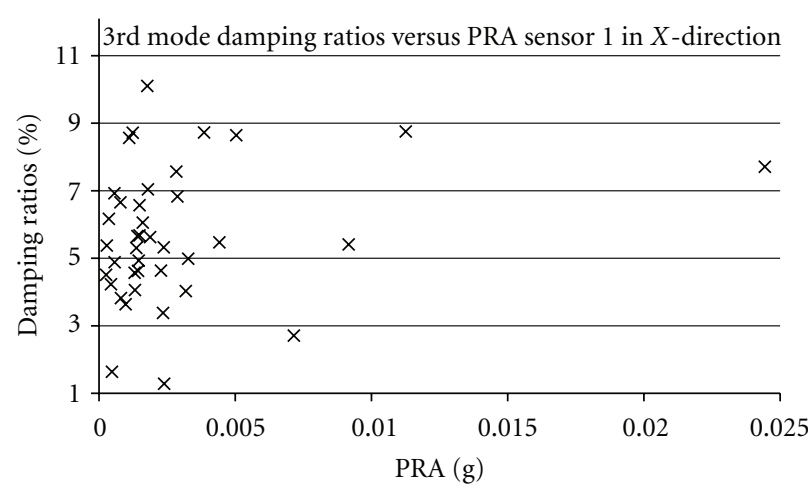

(c)

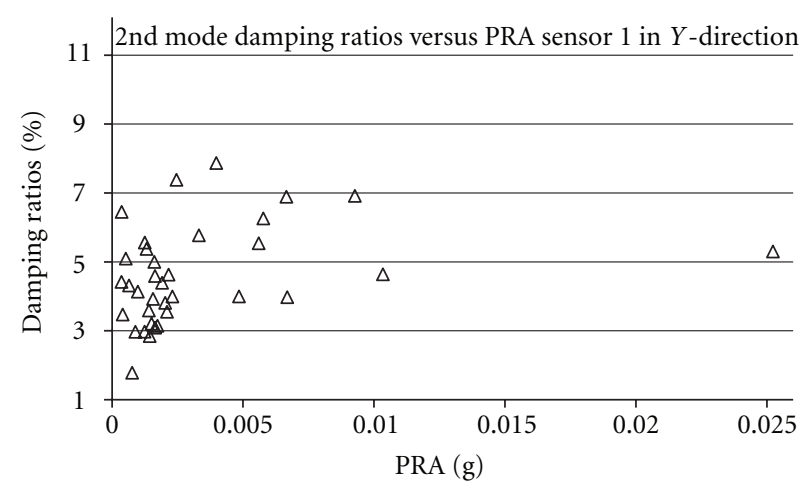

(e)

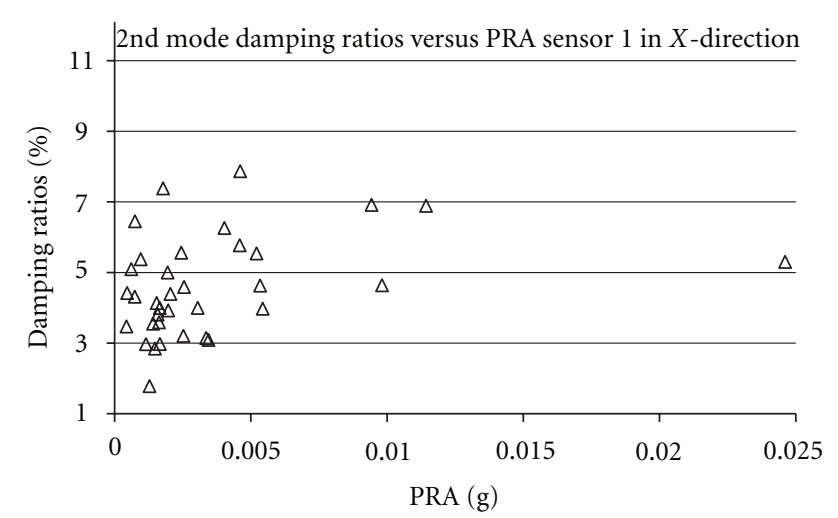

(b)

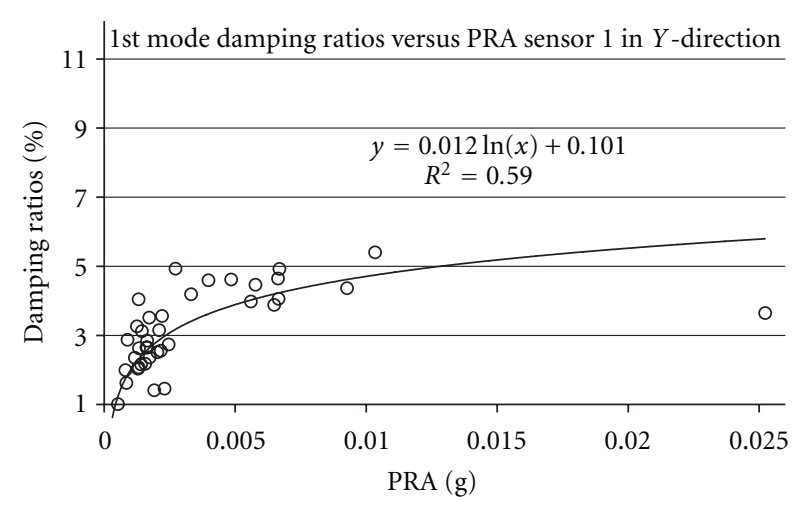

(d)

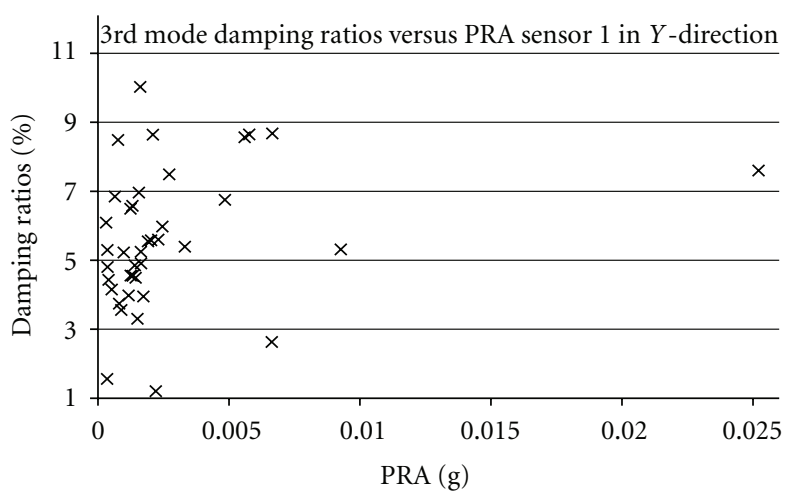

(f)

FIgURE 16: Modal damping ratios of building B for pseudoflexible base case: (a) 1st mode, (b) 2nd mode, (c) 3rd mode versus $X$-direction PRA of sensor 1; (d) 1st mode, (e) 2nd mode, and (f) 3rd mode versus $Y$-direction PRA of sensor 1.

$3.4 \%, 5.6 \%$, and $3.1 \%$ for the flexible base case; for building B, $2.9 \%, 4.5 \%$, and $5.6 \%$ for the pseudoflexible base case and $3.3 \%, 4.6 \%$, and $5.7 \%$ for the flexible base case.

Since the level of excitation, and correspondingly response, is low for the events in the present study, the difference between the pseudoflexible and flexible base model frequencies are not large, nevertheless a clear and consistent trend can be seen of the flexible base frequencies being smaller than their pseudoflexible base counterparts. In the case of damping ratios, a trend of larger damping ratios for the flexible base case is still discernable despite the large scatter of data.

\section{Conclusions}

In this study, seismic responses to 50 low-to-medium intensity earthquakes recorded over a period of more than two years on two three-storey RC concrete frame buildings were 


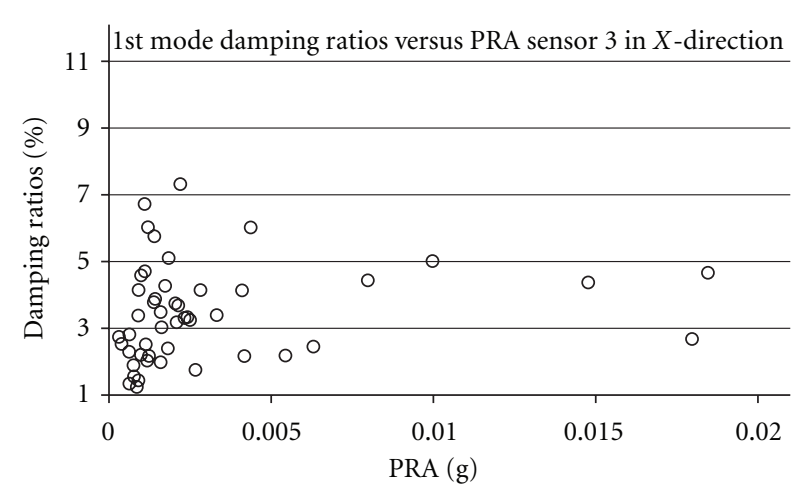

(a)

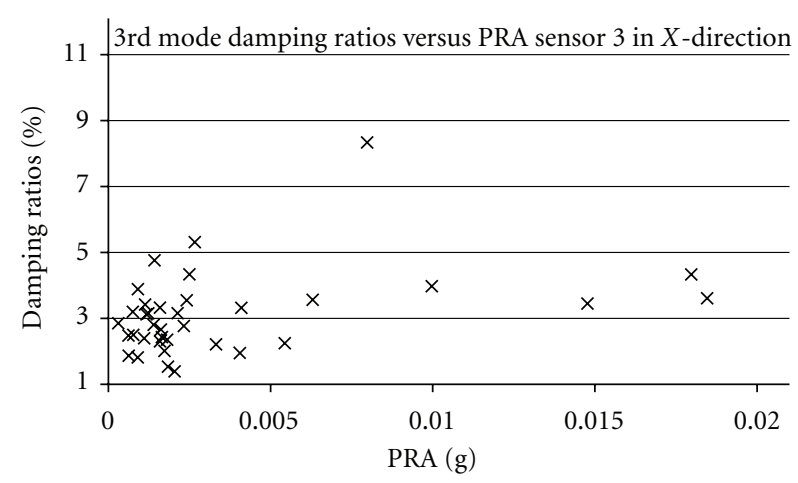

(c)

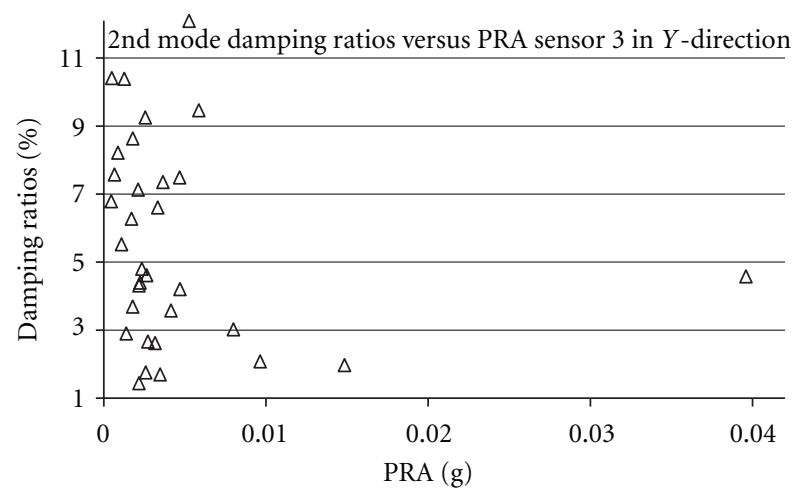

(e)

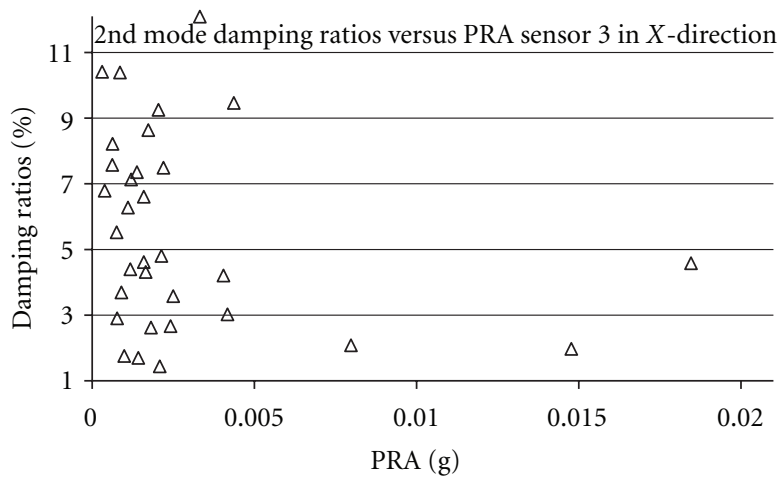

(b)

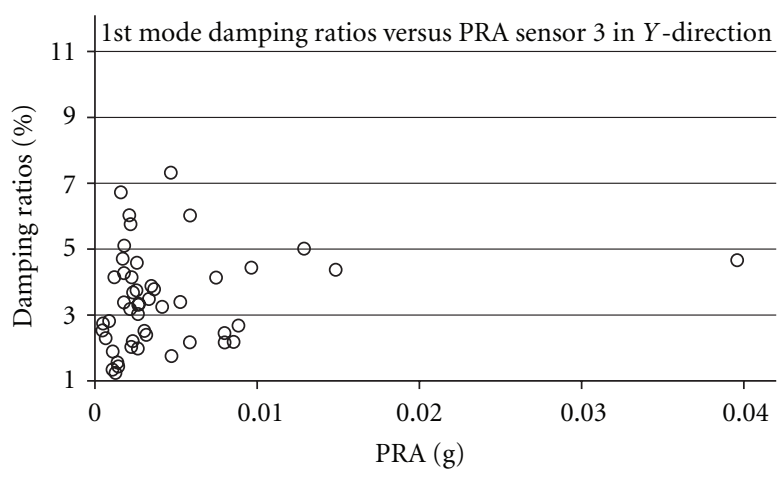

(d)

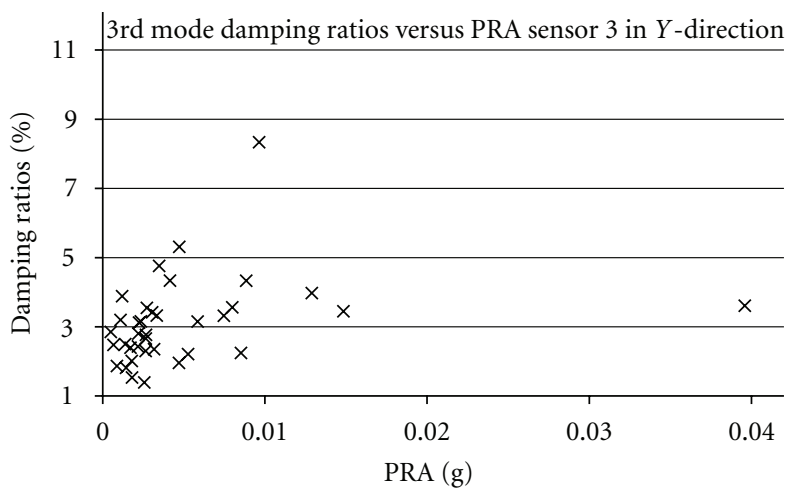

(f)

Figure 17: Modal damping ratios of building A for flexible base case: (a) 1st mode, (b) 2nd mode, (c) 3rd mode versus X-direction PRA of sensor 3; (d) 1st mode, (e) 2nd mode, and (f) 3rd mode versus $Y$-direction PRA of sensor 3.

analysed. Firstly, correlations between PGAs of the free field and those recorded at the building base, and between building base PGAs and PRAs were statistically assessed. Next, system identification of the two buildings was conducted to obtain both pseudoflexible base and flexible base modal frequencies and damping ratios. To evaluate the variation in the modal characteristics, the relationships between the first three frequencies and corresponding damping ratios and PRA were developed.

The main findings of this research can be summarized as follows. (i) PGAs at the free field and PGAs at the building base have very good correlation, as do PGAs at the building base and PRAs.

(ii) The amplification factors between free field PGAs and building base PGA vary between 0.45 and 0.90 , and between building base PGAs and PRAs between 3.16 and 4.44 .

(iii) Modal frequencies have a clear decreasing trend with PRAs that can be reasonably well approximated by a linear dependence on PRA. 


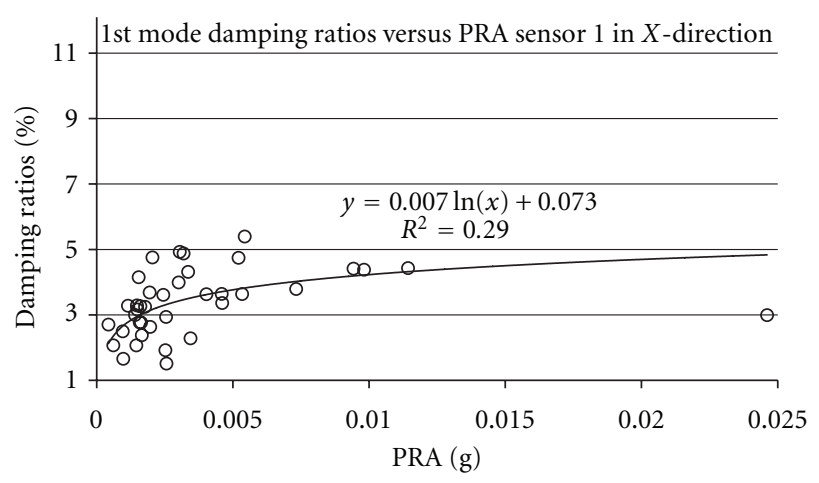

(a)

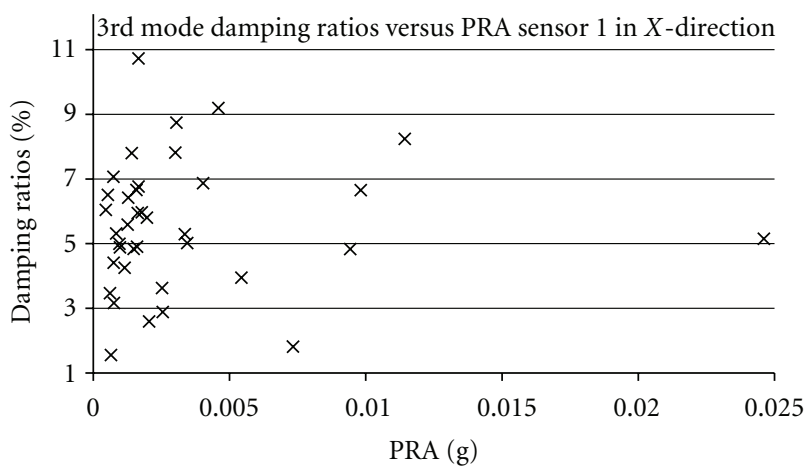

(c)

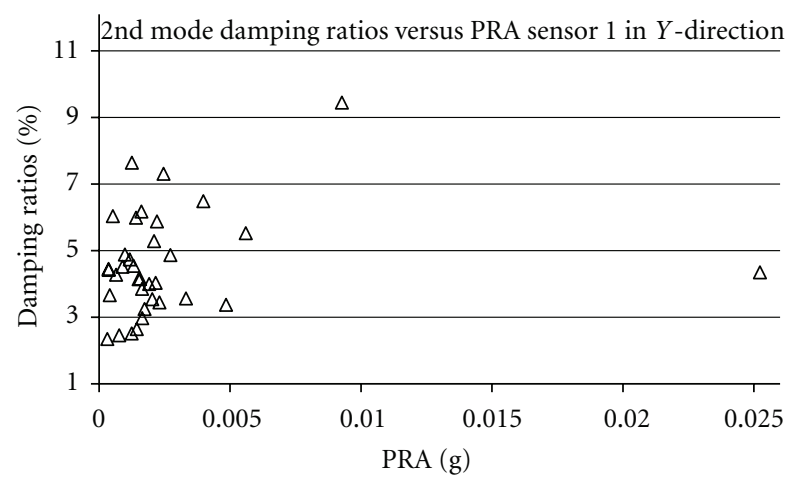

(e)

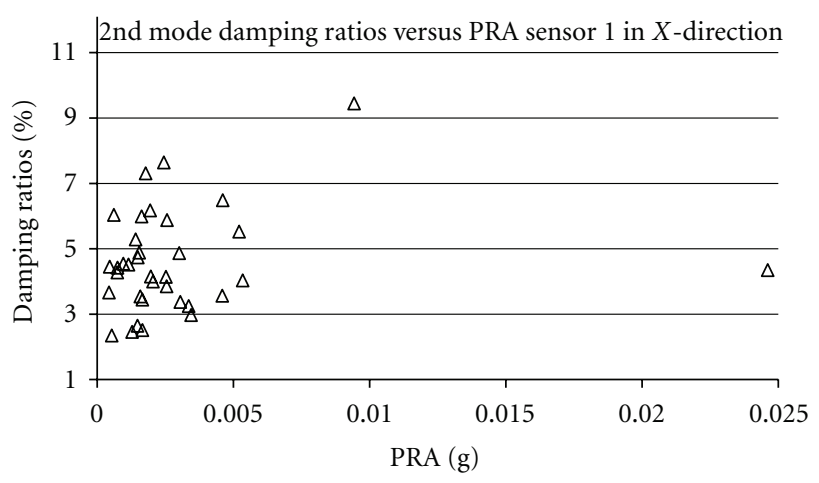

(b)

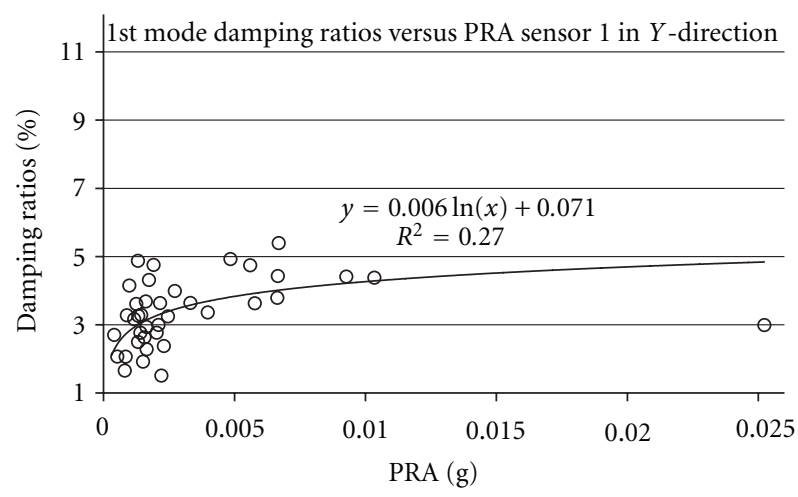

(d)

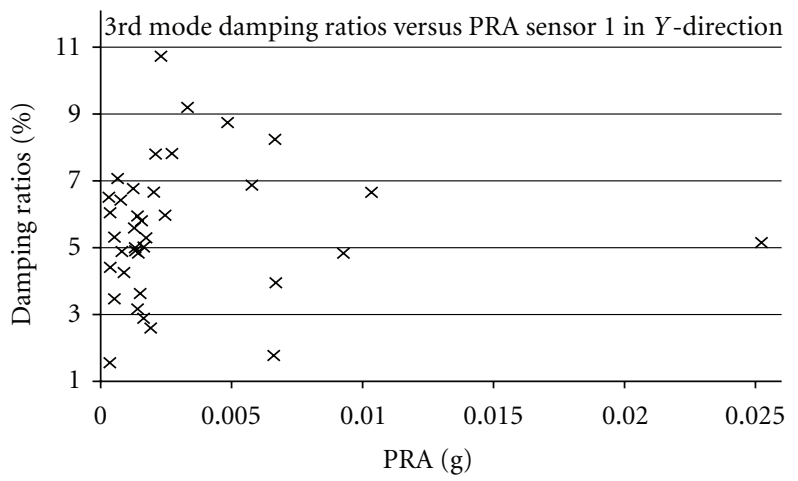

(f)

FIgURE 18: Modal damping ratios of building B for flexible base case: (a) 1st mode, (b) 2nd mode, (c) 3rd mode versus $X$-direction PRA of sensor 1; (d) 1st mode, (e) 2nd mode, and (f) 3rd mode versus $Y$-direction PRA of sensor 1.

(iv) Modal damping ratios are identified with considerable scatter but in some cases show an increasing trend with PRAs.

(v) Regarding soil structure interaction, even for lowto-medium intensity shaking events, the differences in pseudoflexible and flexible base modal dynamic characteristics are noticeable, where the flexible base frequencies are smaller than their pseudoflexible base counterparts, while a reverse relationship applies to the damping ratios.
In future research, a wider set of metrics and other descriptive parameters characterising ground shaking and/or structural response could be considered, for example, peak ground velocity and displacement, duration of strong motion, and direction of earthquake.

\section{Acknowledgments}

The authors would like to acknowledge GeoNet staff for facilitating this research. Particular thanks go to Dr. Jim Cousins, Dr. S. R. Uma and Dr. Ken Gledhill. The first author 
would also like to thank Higher Education Commission (HEC) Pakistan for funding his Ph.D. study.

\section{References}

[1] G. C. Hart and J. T. P. Yao, "System identification in structural dynamics," Journal of Engineering Mechanics, vol. 103, pp. 1089-1104, 1976.

[2] T. Saito and H. Yokota, "Evaluation of dynamic characteristics of high-rise buildings using system identification techniques," Journal of Wind Engineering and Industrial Aerodynamics, vol. 59, no. 2-3, pp. 299-307, 1996.

[3] J. M. W. Brownjohn and P. Q. Xia, "Dynamic assessment of curved cable-stayed bridge by model updating," Journal of Structural Engineering, vol. 126, no. 2, pp. 252-260, 2000.

[4] H. Sohn, C. R. Farrar, F. M. Hemez et al., A Review of Structural Health Monitoring Literature: 1996-2001, Los Alamos National Laboratory, Los Alamos, NM, USA, 2003.

[5] N. Satake and H. Yokota, "Evaluation of vibration properties of high-rise steel buildings using data of vibration tests and earthquake observations," Journal of Wind Engineering and Industrial Aerodynamics, vol. 59, no. 2-3, pp. 265-282, 1996.

[6] M. D. Trifunac, S. S. Ivanović, and M. I. Todorovska, "Apparent periods of a building. I: Fourier analysis," Journal of Structural Engineering, vol. 127, no. 5, pp. 517-526, 2001.

[7] M. Çelebi, "Recorded earthquake responses from the integrated seismic monitoring network of the Atwood building, Anchorage, Alaska," Earthquake Spectra, vol. 22, no. 4, pp. 847-864, 2006.

[8] M. D. Trifunac and M. I. Todorovska, "Recording and interpreting earthquake response of full-scale structures," in Proceedings of the NATO Advanced Research Workshop on StrongMotion Instrumentation for Civil Engineering Structures, pp. 131-155, Kluwer Academic Publications, Istanbul, Turkey, 1999.

[9] M. Celebi and E. Safak, "Seismic response of Transamerica building. I. Data and preliminary analysis," Journal of Structural Engineering, vol. 117, no. 8, pp. 2389-2404, 1991.

[10] M. Celebi and E. Safak, "Seismic response of Pacific Park Plaza. I. Data and preliminary analysis," Journal of Structural Engineering, vol. 118, no. 6, pp. 1547-1565, 1992.

[11] E. Şafak, "Response of a 42-storey steel-frame building to the $\mathrm{MS}=7.1$ Loma Prieta earthquake," Engineering Structures, vol. 15, no. 6, pp. 403-421, 1993.

[12] J. P. Stewart and G. L. Fenves, "System identification for evaluating soil-structure interaction effects in buildings from strong motion recordings," Earthquake Engineering and Structural Dynamics, vol. 27, no. 8, pp. 869-885, 1998.

[13] J. E. Luco, "Soil-structure interaction and identification of structural models," in Proceedings of the 2nd ASCE Conference on Civil Engineering and Nuclear Power, pp. 1-31, American Society of Civil Engineering, Knoxville, Tenn, USA, 1980.

[14] C. C. Lin, J. F. Wang, and C. H. Tsai, "Dynamic parameter identification for irregular buildings considering soilstructure interaction effects," Earthquake Spectra, vol. 24, no. 3, pp. 641-666, 2008.

[15] P. Van Overschee and B. De Moor, "N4SID: subspace algorithms for the identification of combined deterministicstochastic systems," Automatica, vol. 30, no. 1, pp. 75-93, 1994.

[16] G. L. Molas and F. Yamazaki, "Neural networks for quick earthquake damage estimation," Earthquake Engineering and Structural Dynamics, vol. 24, no. 4, pp. 505-516, 1995.
[17] A. Elenas and K. Meskouris, "Correlation study between seismic acceleration parameters and damage indices of structures," Engineering Structures, vol. 23, no. 6, pp. 698-704, 2001.

[18] R. Riddell, "On ground motion intensity indices," Earthquake Spectra, vol. 23, no. 1, pp. 147-173, 2007.

[19] O. R. de Lautour and P. Omenzetter, "Prediction of seismicinduced structural damage using artificial neural networks," Engineering Structures, vol. 31, no. 2, pp. 600-606, 2009.

[20] S. R. Uma, J. X. Zhao, and A. B. King, "Seismic actions on acceleration sensitive non-structural components in ductile frames," Bulletin of the New Zealand Society for Earthquake Engineering, vol. 43, no. 2, pp. 110-125, 2010.

[21] L. Berto, R. Vitaliani, A. Saetta, and P. Simioni, "Seismic assessment of existing RC structures affected by degradation phenomena," Structural Safety, vol. 31, no. 4, pp. 284-297, 2009.

[22] P. Van Overschee and B. De Moor, Subspace Identification for Linear Systems, Kluwer Academic Publishers, Dordrecht, Netherlands, 1996.

[23] D. J. Ewins, Modal Testing: Theory, Practice and Application, Research Studies Press, Baldock, UK, 2000.

[24] A. S. Veletsos and V. D. Nair, "Seismic interaction of structures on hysteretic foundations," Journal of Structural Engineering, vol. 101, no. 1, pp. 109-129, 1975.

[25] J. Bielak, "Dynamic behavior of structures with embedded foundations," Journal of Earthquake Engineering and Structural Dynamics, vol. 3, no. 3, pp. 259-274, 1975.

[26] D. Montgomery, E. A. Peck, and G. Vining, Introduction to Linear Regression Analysis, Wiley, New York, NY, USA, 2001.

[27] R. Steel and J. Torrie, Principles and Procedures of Statistics, McGraw-Hill, New York, NY, USA, 1960. 

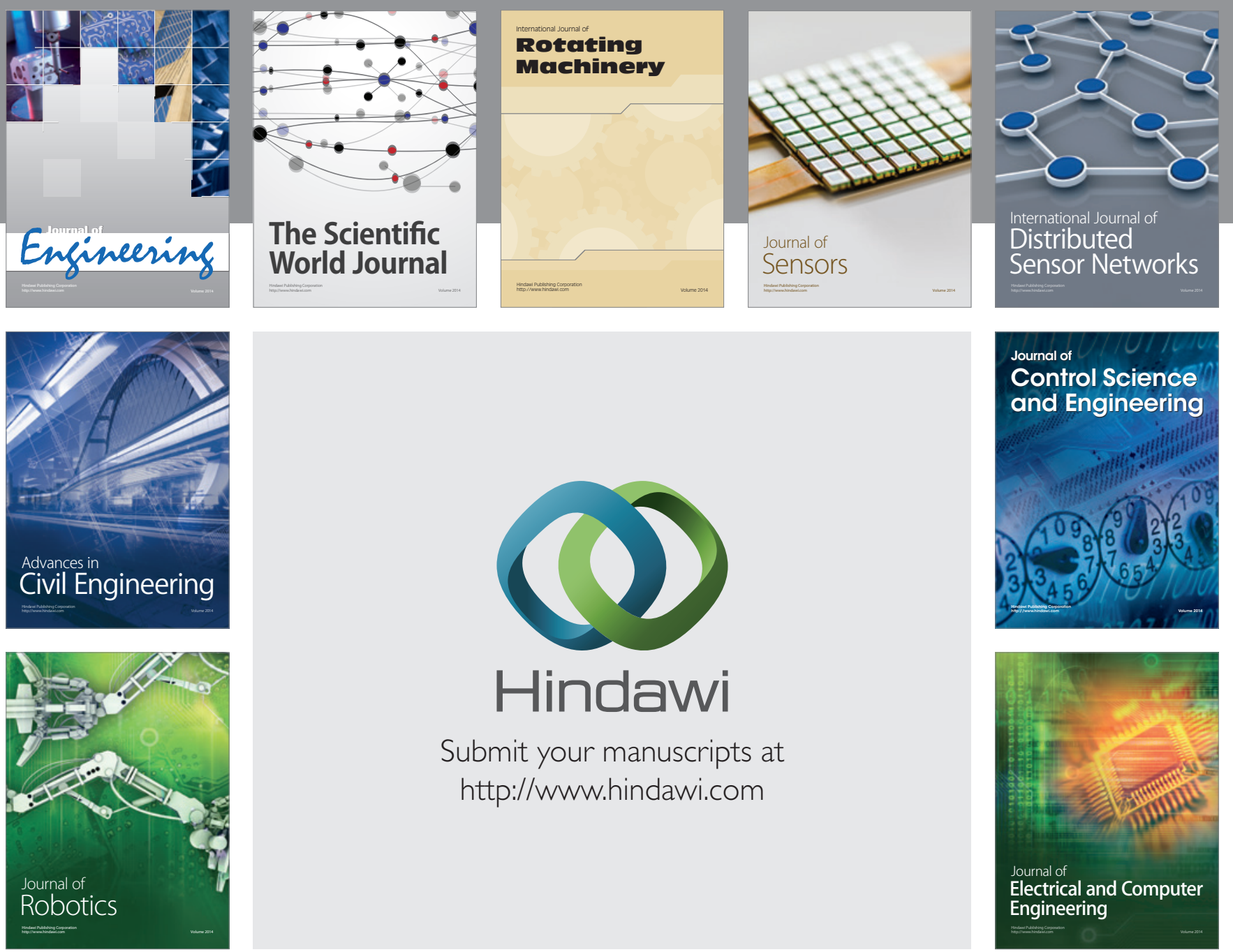

Submit your manuscripts at

http://www.hindawi.com
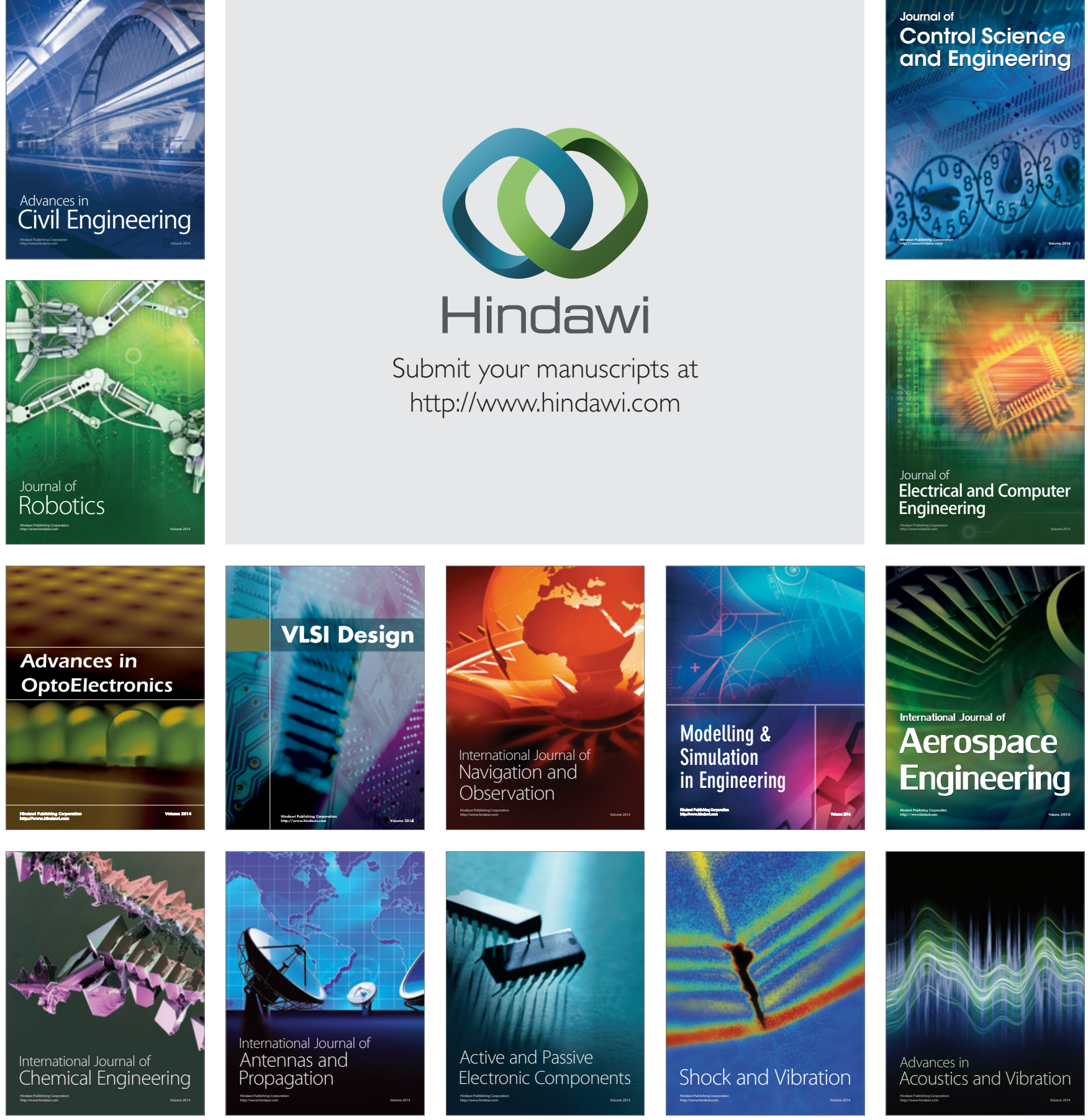